John Raven*

\title{
Some Abuses of "Science," Logic, and Authority Illustrated from Research in Education
}

\section{ABSTRACT}

In this paper, problems with the philosophy and research relating to various interpretations of "closing the gap" in educational achievement are used to open up a discussion of, and illustrate, the process whereby a narrow interpretation of "science" and neglect of systemic thinking result in the generation of huge amounts of dangerous and misleading misinformation and thence the generation of draconian and destructive policies. The paper opens by returning to an unfinished debate arising out of a summary of the unanticipated and counterintuitive effects of interventions designed to close the "attainment" gap between more and less advantaged pupils. This is used to illustrate the importance of studying the unintended as well as intended outcomes of interventions and the importance of considering whether those outcomes are desirable. More of the problems facing those who seek to contribute to evidence-based policy are then illustrated, via a discussion of an "illuminative" evaluation of competency-oriented, project-based, education conducted in the environment around a number of schools, to open a discussion of the need for comprehensive evaluation of educational-and other-projects and policies. "Comprehensive evaluation" implies the evaluation of all short and long term, personal and social, desired and desirable, and undesired and undesirable effects of the programmes and policies under investigation. When this criterion is applied to the vast number

* Correspondence regarding the paper should be sent to: John Raven, 30 Great King St., Edinburgh EH3 6QH, e-mail: jraven@ednet.co.uk, Website: http:/ / eyeonsociety.co.uk 
of published evaluations of school effectiveness it emerges that most fall well short of the mark. Worse than that, most of their conclusions are nothing less than seriously misleading and damaging. The generation of such misleading information is much more widespread and serious than that exposed by the "replication crisis." It is argued that, in essence, it stems from the pervasive deployment of non-systemic (viz. "reductionist") science. A range of serious deficits in the thinking and methodology of psychologists and educational researchers associated with this approach are then discussed. It is concluded that it is vital for social scientists to do what they can to rectify the situation.

KEYWORDS: systemic thinking; reductionist science; comprehensive evaluation; professionalism; competence; Forrester's law; abuses of authority; fascism; hierarchy; emergence; sociocybernetics; social forces; turning psychology inside out; recursion; teacher competence; generation of misinformation; destruction of Gaia; social Darwinism; teaching versus education; images of "science."

\section{BACKGROUND}

One day, somewhere in the spring of 2017, on opening my copy of The Psychologist out fell a "call for papers" relating to Closing the Attainment Gap for Educational and Child Psychology.

Now, ever since I became involved in an evaluation of an Educational Home Visiting scheme in 1976 (Raven, 1980b) ... in the course of which we found that the way the problem was framed by psychologists and administrators was seriously out of kilter with the way the issues to which it was designed to relate were perceived by the parents concerned and their children .... I have been sceptical about the way in which psychologists and administrators frame issues in education.

Much later, I became even more concerned about the way in which the same assumptions were built into the deeply intrusive Scottish Government's Children and Young People's Act. ${ }^{1}$ Through this, a "named person" holding some position in the administrative structure (e.g., head teacher or social worker) has to be appointed for every "child" (aged minus 6 months to 22 years 
of age) to visit their homes on a regular basis. These "named persons" are provided with two sets of 60-item tick-box questionnaires named, in an Orwellian manner, GIRFEC ${ }^{2}$ and SHANARI ${ }^{3}$ which they have to complete on each visit. They also have access to all the family health, social, and criminal records (access which the parents themselves do not have). And they have the right to require parents and children to, among other things, attend "remedial" programmes (including "remedial" parent-education programmes) and, in the event of failure to comply, have the children taken into (uncaring) care.

The questionnaires have been drawn up by bureaucrats on the basis of summaries of the available so-called policy-related research evidence that have been compiled through a progressively-narrowing recursive process whereby researchers respond to "calls for proposals" to summarise research in an area framed, through the politico-bureaucratic process, in such a way as to exclude other perspectives and thus cyclically reinforce the framing of "the problem" and the range of research that can be funded.

While there is, indeed, some, marginally-debated, legislation, drawn up at the behest of some conspicuously power-oriented politicians, at the base of all this activity, most of what happens has been generated through a cascade of activities of the kind perhaps made most visible by Stanley Milgram (Milgram, 1974), (Roberts, 2018b), whereby many people in public service hierarchies seem only too willing to go along with enacting, enforcing, and, indeed, elaborating, the, already authoritarian, legal requirements even at the direct interface between the system and its "clients."

I mention all this because any kind of objection to participation in this process requires levels of professional commitment going well beyond those called for in most people's job descriptions ... and it often involves jeopardising one's job.

And that is an issue I have to come back to ... for what is the role of professional organisations like the Polish Psychological 
Association (Polskie Towarzystwo Psychologiczne) in supporting such professional objection, and questioning the framing the questions which get asked in the course of formulating what is Orwellianly termed "evidence based policy"?

When Educational and Child Psychology's "call for papers" relating to "closing the attainment gap" arrived, I could not resist the temptation to return to an unfinished debate which occurred in the pages of The American Psychologist around 2005.

Ceici and Papierno (2005) had published a (welcome) paper entitled "The rhetoric and reality of gap closing: When the "have-nots" gain but the "haves" gain even more' in which they first showed that many interventions deigned to close "the attainment gap" (defined in a variety of ways) made use of strategies which ended up increasing that gap.

But they then went on to suggest that one could envisage circumstances in which this unintended and counterintuitive effect would be highly desirable ... for example if it resulted not only in higher levels of literacy all round but, in the end, more excellent scientists and engineers on whom, they felt, the future of society depends.

After seeing their paper, I submitted a Comment entitled More problems with Gap Closing Philosophy and Research in which I said, among other things, that Ceici and Papierno's paper was imbued with a Western ... and particularly American middle-class researchers' ... single-factor, hierarchical, viewpoint which essentially denied many pupils the opportunity to develop one or other of a wide range of socially important talents. Had those who designed the interventions and the evaluations paid more attention to these other outcomes, the gap in what is misleadingly termed "academic achievement" would have paled into relative insignificance. Instead, through a recursive process, the focus on a single outcome in the evaluations rendered those other talents increasingly invisible.

Papierno \& Ceci (2005) responded in a paper entitled Beyond the American Context in which they kind-of claimed that the quest 
to use the "educational" system primarily to gain entry to high status jobs was not culturally limited.

I responded in a further paper entitled Papierno \& Ceci Miss the Point (Raven, 2006a) in which I pointed out that the quest to use the "educational" system in this way was not even universal within our own society, never mind cross-culturally, and that it was important to consider the implications.

The outcome of this unfinished debate was that when the "quest for contributions" for Educational and Child Psychology arrived, I wrote back giving links to the previously mentioned articles and saying that I would be delighted to elaborate.

The result was a phone call from the guest editor from which it was clear that she was not merely interested but enthusiastic!

But, as I came to work on the article ... which actually occupied me from spring to autumn of 2017 ... it gradually emerged that, really, the biggest gap requiring closure was that between the objectives of education as perceived by most parents, pupils, teachers and businessmen ... (which have to do with helping pupils to develop and gain recognition for their own particular talents) and

(1) those that actually get attention in schools

(2) those that have been studied in most "evaluations" of educational effectiveness.

How could the studies in the last group possibly be considered to be objective/scientific evaluations of the relative effectiveness of a variety of educational programmes when they made no attempt to assess progress toward or away from what most people consider to be the main goals of education?

But then, as I reviewed the research which had been published since the mid-1980s, I became progressively more and more appalled at:

- the quality of the available research,

- the extent to which most "evaluation" studies failed to look at undesired and undesirable effects of the policies they were claiming to evaluate, 
- the pervasive failures in logic,

- the shocking interventions which the authorities had, on the basis of the flimsiest of evidence, commanded in what can best be viewed as an authoritarian, even fascist, manner.

These seemed much more serious than those which had come to light in the so-called "replicability crisis" with which so many people have become so concerned in the last few of years.

And all raised serious questions about the role of professional Associations in failing to take steps to remedy the situation.

I will return to all this later, but let me first explore some of the issues more fully.

THE BIGGEST GAP IS THAT BETWEEN THE GOALS OF EDUCATION AND WHAT HAPPENS IN SCHOOLS AND IS STUDIED BY EVALUATORS

Surveys among teachers, pupils, ex-pupils, parents and employers conducted in many countries over the past 50 years (Raven, 1994) show that the vast majority think that the main goals of education are to nurture qualities like

- "the confidence and initiative required to introduce change" (actually, the most widely endorsed goal among our adolescent pupils),

- problem-solving ability,

- the ability to work with others,

- the ability to make one's own observations,

- the ability to communicate,

- leadership ability, and

- the ability to understand how organisations and society work and play an active part in them.

But these studies also show that, more generally and more importantly, the main goals include helping people to develop, and get recognition for, the diverse, often idiosyncratic, talents they possess. 
The objectives said to be very important did include helping people to acquire the credentials that appear to control entry to jobs.

But the significance to be attached to this has to be tempered by the fact that it was widely recognised that the formal knowledge on which such certificates are based is, in reality, unimportant. It is out of date when it is taught, quickly forgotten, and does not relate to peoples' needs.

We confirmed the accuracy of these opinions through studies of competence in the workplace (Raven 1984/1997b; Raven \& Stephenson, 2001; Spencer \& Spencer, 1993).

Yet, despite their acknowledged importance, few schools pay much attention to these wider character/talent-development goals, concentrating, instead, on helping pupils to gain certificates based on the ability to regurgitate temporary ${ }^{5}$ knowledge of tiny snippets of-out-of-date information arbitrarily extracted from the vast pool of knowledge that is available-knowledge which is generally (and necessarily ${ }^{6}$ ) unrelated to their life or employment needs.

\section{SOME SCHOOLS DO ACHIEVE THEM}

Yet some schools do achieve these goals ... and it is important to discuss one way in which they can do so via a particular example, not only because the case is of interest in its own right, but also because it highlights a number of basic conceptual and methodological issues that psychologists need to address.

The example comes from a study of a mixed age (8-11), mixed ability, class ${ }^{7}$ conducted some years ago (Raven, Johnstone, \& Varley, 1985; Raven, 1994, 2012a).

Most of the pupils' education took place through a series of projects conducted in the environment around the school. 
At the time we studied them, their project involved trying to do something about the pollution in the local river.

Some pupils decided that the first thing to do was to measure the pollution in the river. They set about collecting samples of the river water and trying to analyse it. This took them to the not-so-local university where they worked with lecturers trying to engage with this-apparently difficult-problem. Note that these pupils were developing the competencies of the scientist: The ability to identify problems, the ability to invent ways of investigating them, the ability to obtain help, the ability to familiarise themselves with a new field, and the ability to find ways of summarising information. Other pupils decided that more progress was to be made by studying the dead fish and plants along the river bank. Still others argued that all this was beside the point: The river was clearly polluted: the problem was to get something done about it. Some then set about drawing pictures of dead fish and plants from the river bank with a view to releasing community action. The objective was not to depict what was seen accurately, but to represent it in such a way as to evoke emotions that would lead to action. While the "scientists" mentioned above sought to report the results of their work in what might be termed a classic academic format, other pupils again argued that that was irrelevant and set about generating slogans, prose, and poetry that would evoke emotions that would lead to outrage and action. Thus the criteria for what constituted effective reading and writing differed markedly from those which dominate most classrooms and they varied from pupil to pupil. Still other pupils argued that, if anything was to be done about the river, it was necessary to get the environmental standards officer to do his job. (It turned out that he knew all about the pollution but had done nothing about it.) This led some pupils to set up dominolike chains to influence politicians and public servants. This in turn led the factory that was causing the problem to get at the pupils' parents saying that, unless this teacher and her class was 
stopped, they would all lose their jobs. Unabashed, some pupils set about examining the economic basis for the factory's claims.

Note that this teacher was not so much concerned with enhancing pupils' specialist knowledge in each of these areas as to nurture a wide range of different competencies in her pupils. These competencies were not limited to substantive areas of investigation but also included the ability to contribute to group processes, including such things as the ability to put people at ease, the ability to de-fuse the intolerance which develops between people who contribute in very different ways to a group process (e.g., the intolerance of "artists" for "scientists"), the ability to publicise the observations of the quiet "ideas person," and the ability to "sell" the benefits of the unusual educational process to parents. The teacher in fact devoted considerable attention to highlighting the different types of contribution which different children were making to the group process. As a result, they stopped thinking of each other in terms of "smart vs. dumb" and instead noted what each was good at.

Note the "measurement" model implied here. The words I have used imply, as a background, some kind of descriptive framework of the kind used in biology (Raven, 2020). Pupils are not being rated on "scales." More specifically, the pupils are not being graded on a scale running from "high" to "low" "ability." All pupils are good at something; the question is: "What?"

Here we have the development of a wide variety of high-level competencies* the "existence" of each of which depends on tap-

* I use the word competencies to refer to emotional predispositions to engage in fairly specific, but complex, activities having cognitive, affective, and conative components in effective ways in a variety of situations. As such, they involve much more than cognitive knowledge and mental or sensory-motor skills. Even the requisite "knowledge" is largely tacit, consisting of knowledge (often of ways of doing things) located in people's hearts and hands-such as emotionally-based predispositions to react to non-verbal feedback from motor activities and other people's body language. The crucial thing is that compo- 
ping each individual's motives and creating situations in which they are able to develop and display their idiosyncratic talents and patterns of competence.

But that is not all. Without the context of others engaged in related tasks they could not have developed these competencies.

Indeed many of those talents could only exist in those contexts.

Outwith that context those concerned could not even be said to possess them.

They were emergent competencies.

Not only that, the class as a whole displayed an emergent property which might be described as "collective intelligence" or "a climate of enterprise."

Note that this emergent competence of the group, qua group, did not exist in anyone's head. Indeed it did not "exist" anywhere. It was a systems property. ${ }^{8}$ Yet it was a real emergent property just as the properties of copper sulphate are distinct from the properties of copper, sulphur, and oxygen (Raven 2008, 2012b).

Nevertheless, it was produced by, and reciprocally affected, the emergent individual competencies of the pupils in the group.

Note, too, that the system itself was able to learn in ways not represented in anyone's head but in exactly the same pervasive way as human beings, as organic systems, learn.

\section{TEACHER COMPETENCE}

And, what of the competence of the teacher ${ }^{9}$ to orchestrate this extraordinary developmental process ${ }^{10}$ ?

Just as the educational process described here largely took place in the environment outside the school so, too, did the work of the teacher.

nents of this feedback are sub-consciously selected and intensively engaged to produce effective action, mental or physical. 
The teacher spent a great deal of time with the parents of the children to legitimise the educational process she was implementing.

She spent time with school administrators and the heads of secondary schools undermining their faith in traditional tests as meaningful measures of such things as reading and mathematical ability ... and assuring them that the futures of these children in their schools and the schools themselves (via performance-based assessments) were not being jeopardised as a result of the activities in which they were engaged.

These components of competence deployed by these teachers as managers of pupil development can be brought together in Figure 1, which was developed by Lees (1996) as a basis for discussing managerial competence in other organisations.

What it shows is that:

- Effective teachers, and managers more generally, have first to develop a very different, if largely unverbalised, image of the varieties of human talent and their development from the conventional human resource management view sketched in the central box.

- They have to think about the individual motives and talents of each of their pupils or subordinates and create situations in which those pupils or subordinates can work together to develop those talents on an individual and collective basis. ${ }^{11}$

- They have to abandon conventional notions of selection and reward. ${ }^{12,13}$

- They have to think about the emergent properties of groups. Note that these things cannot be done for them by anyone else (such as a HR specialist). It is an integral component of their job. 


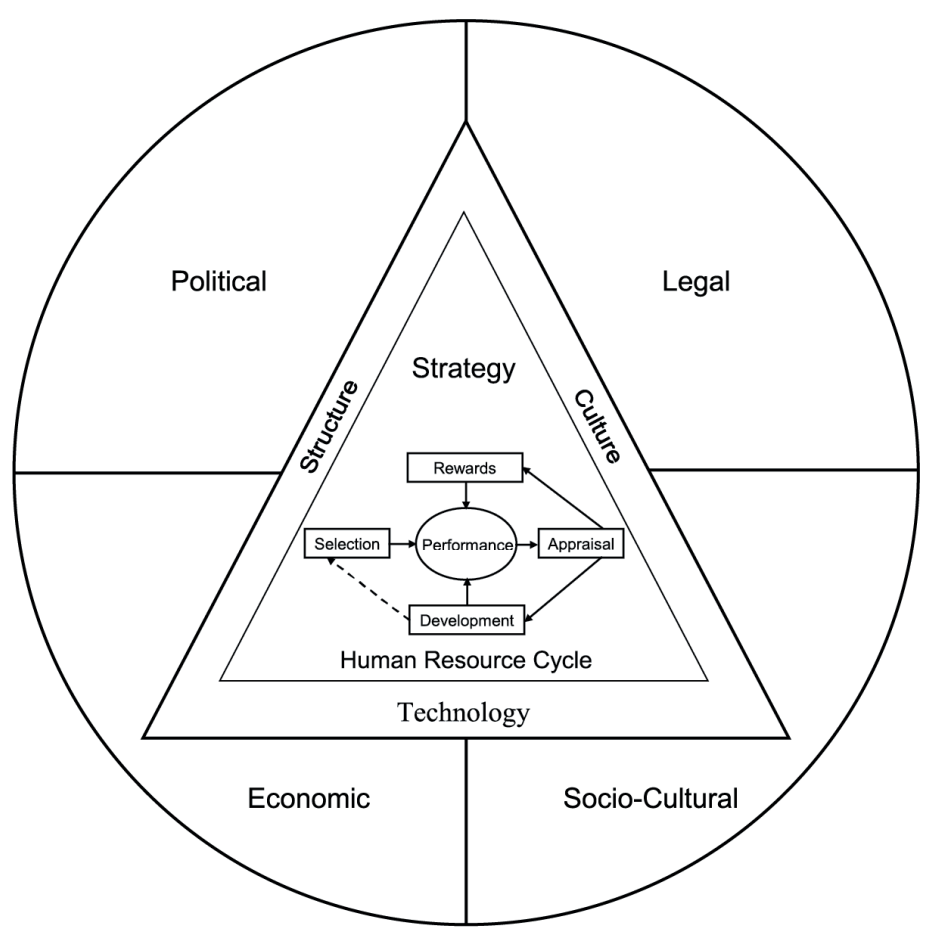

Figure 1. Domains of Managerial Competence. Reproduced, with permission, from Lees (1996).

Beyond that, they have to intervene in the technology, culture, and structures of the organisations within which they work.

Teachers have to intervene with parents, administrators, head teachers, and other teachers who do not share their objectives and their levels of commitment toward them.

They have somehow to ameliorate the effects of the constraints which institutionalised assessment and selection procedures place on their work. ${ }^{14}$

As if that were not enough, they have to intervene in wider civic processes. 
In business settings, managers have to do such things as arrange for what might be considered to be industrial espionage to find out what their competitors are doing and persuade governments to enact regulations requiring the use of their own products or services.

Note the professionalism of the work. It involves people going beyond, even protesting, their job descriptions.

If the kind of work the teachers whose work we have summarised here is to be more widely disseminated, teachers and others will need, through their professional organisations, to influence the wider social, legal, and political context within which they work. ${ }^{15}$

I could go on now to discuss a series of other vitally important reasons-all of which demand the urgent attention of psychologists-why schools neglect their main goals. But these are discussed in some detail in other places (Raven, 1994, 2012a, 2017) while my aim here is to highlight some major deficits in scientific research and logic ... and the behaviour of authorities ... which came to concern me more and more as I reviewed research and writing bearing on the "closing the gap" discussion and which, in sense, lie within a domain over with which psychologists themselves would appear to have more control.

PROBLEMS WITH THE PHILOSOPHY AND CONDUCT OF MUCH EDUCATIONAL RESEARCH

While I was shocked by evidence of the sort of thing on which the so-called replication crisis has focussed on-significance hunting, generalisation from small unrepresentative samples, and so on-I do not feel that I need to discuss these things here. They have been subject to a flood of soul-searching conferences elsewhere (although my own impression is that they arise mainly 
from neglect of the recommendations of the APA Task Statistical Inference $\left.{ }^{16}\right)$.

Here I will present a case for believing that these things pale into insignificance when compared with the manufacture of misinformation through our current research process.

The reality is that the majority of studies claiming to offer contributions to the evaluation of educational policies and programmes-and guidance on educational practice-are seriously misleading.

Contrary to the impression they seek to create, they cannot be considered to constitute good science.

And they often lead to, or support, policies which have many harmful consequences.

These studies, and the policies associated with them, must therefore be considered unethical.

Worse, the failure of the researchers concerned to draw attention to the limitations of their work, or challenge the policies based upon them, must itself be considered unprofessional and unethical.

I have attempted to arrange what I said in my first, discursive, attempt to write about these things ${ }^{17}$ under the following headings:

- Non-systemic, reductionist, Science

- Problems arising from the dominant psychometric model

- Problems with the conceptualisation and assessment of home and school environments

- Failure to engage in conceptual or critical thinking

- Deficits in logic

- More specific methodological deficits

- Professional failures

- Abuses of authority

This is followed by a discussion of the question:

- How has all this come about? 
Then, after drawing out some general CONCLUSIONS, I discuss

- Implications for members of the scientific community-and the Polish Psychological Association (Polskie Towarzystwo Psychologiczne)

NON-SYSTEMIC (REDUCTIONIST) SCIENCE

As will gradually emerge, most of the conclusions drawn from the studies I reviewed ${ }^{18}$ have been rendered invalid or seriously misleading because their authors failed to set their results in a systemic context ... that is, they failed to address the problems posed by non-systemic (reductionist) science (Raven 2016).

It is easiest to illustrate this by beginning with one striking example.

Failure to include measures of progress toward, or away from, the main goals of education when generating what are presented as evaluations of educational policy to be used when generating "evidence-based" policy.

The tens of thousands of evaluations of educational policy which are brought together in Hattie's (2009) meta-analysis of 800 meta-analyses of the relative importance of a variety of factors possibly contributing to educational "achievement" rarely report the relative merits and demerits of those programmes from the point of view of recognising and nurturing the huge range of diverse talents pupils possess (which, as we have seen, is widely believed to be the main goal of the system and is in fact implied by the term "education" itself) ... diverse talents which are crucial to creating the climates of innovation on which our future as a species depends. 
Thus there is no way in which the benefits of such programmes can figure in discussions of policy options which follow from publication of these reports.

And no way in which teachers and schools which do achieve the main goals of education can get credit for their efforts.

Actually, it is worse than that. By not reporting on these things, these evaluations, (i) render these outcomes largely invisible, (ii) discredit those educational programmes which do nurture them, and (iii) fail to reveal that about one third of pupils are seriously damaged by the current system (Raven,1994; Anderson 2001).

The consequences are horrific

These gross deficiencies in these studies reinforce the tendency of the "educational" system to concentrate on teaching (putting in) instead of educating (drawing out the diverse talent of the pupils) and, in this way, contribute enormously to the process whereby the system's sociological function of legitimising hierarchy and a divided society comes to dominate over its educational function (nurturing high level competencies and nurturing each student's particular talents).

In technical terms, what happens offers one illustration of Campbell's law (Campbell, 1979).

This asserts that

he introduction of any quantitative measure, or standard, into the evaluation of any activity has the effect, not only of leading those concerned to focus only on gaining high scores on those measures by whatever (underhand) means possible and to neglect the main goals of the system, but to the corruption of the very measures themselves. 
One factor contributing to this situation is that there are no accepted "measures" of the huge range of talents pupils have the capacity to develop.

Asking why this should be itself actually raises an important question about the way in which "science" is currently perceived by most educational and psychological researchers because, in reality, a descriptive framework, akin to that used in the biological classification of plants and animals, would be required to record those multiple talents and an ecological framework grounded in such things as symbiosis would be required to discuss their nurturance and functioning.

Be that as it may, another thing that it is important to note here is the counterintuitive conclusion that the seemingly laudable requirement that "only reliable and valid measures shall be used in programme evaluation" results in evaluations which are anything but scientific or objective.

More generally, we have to ask "on what basis can the thousands of studies of 'school effectiveness' which contributed to Hattie's metaanalysis claim to be offering 'objective' evaluations of educational policy and school effectiveness?"

Yet objectivity is widely considered to be the hallmark of science.

Comprehensive Evaluation

In practical terms, what we see here is a failure to mount comprehensive evaluations of the activities under review.

Comprehensive evaluation would require that an attempt be made to document all the

- personal and social,

- short and long term,

- intended and unintended,

- desired and desirable, and 
- undesired and undesirable effects of the activity.

What is good for some of the individuals involved may be bad for others; what is good for the individuals may be bad for society; what is good in the short term may be bad in the long term.

Undesired and undesirable outcomes may outweigh desired and desirable ones.

And the criteria for attributing the labels "good" or "bad" will vary from person to person.

So another base-line conclusion to be drawn out of this discussion it is that

the quality of an evaluation is to be judged more in terms of its comprehensiveness - i.e. the extent to which it yields a rough fix on all important inputs and outcomes-than in terms of the accuracy of its assessments of any one variable.

This has major implications for the assessment of research reports.

The role played by Neglect of Systemic Thinking and Enthrallment with Reductionist Science

The failure to even attempt comprehensive evaluations stems in part from an attachment to the notion that science is best progressed-even primarily about-studying the relationship between one experimental and one dependent variable at a time in order to establish causal relationships. ${ }^{19}$

Stated explicitly and revealingly, the basic philosophical position is that "There are all sorts of things going on here, but, in order to advance understanding, we can ignore most of these things and only find out whether, other things being equal, this input affects this outcome." 
Unfortunately, failure to set such studies in the context of a wider systemic perspective has resulted in conclusions which are often seriously misleading and often deeply destructive.

This may be illustrated by reference to some agricultural research (Shiva, 1998). Endless studies have been conducted to assess the relative benefits of various pesticides and fertilisers from the point of view of increasing crop yields.

What these studies generally fail to do is to reveal their effects on such things as:

- the future fertility of the soil (itself an emergent property stemming from the complex interactions between multiple complex organisms since plants are unable to absorb nutrients directly from the soil),

- the effects, via the food chain, on a wide range of species (including ourselves),

- the diversity of species living in complex symbiotic relationships with human beings.

I would go so far as to argue that, cumulatively, such studies, combined with the narrow application of their conclusions, constitute the greatest threat to Gaia that has ever existed ... worse than the destruction inflicted by largest meteorite.

Among other things, the overall effect of studies which fail to report outcomes like those mentioned above has been to justify and facilitate the mining and release of the $\mathrm{CO}_{2}$ which had been salted away to facilitate the evolution of life and the plunder of the planet's resources in such a way as to result in the destruction of the soils, seas, and atmosphere, that is to say, our habitat.

Had the studies been more comprehensive, the outcomes of the activities concerned would have been more likely to be viewed as unconscionable.

Many would claim that these oversights merely reflect failure to behave ethically-i.e. failure to consider the long term effects of one's actions-(which is bad enough). 
But my own claim is that they stem from the application of a distorted form of science in which one is encouraged to study the relationship between one independent and one dependent variable at a time and neglect the many other, mainly systemic, processes involved.

Many would accept the fertiliser example but fail to recognise the same process at work in the educational area.

In fact, exactly the same process can be discerned within the work of Ceci and Papierno mentioned earlier.

First they fail to notice the recursive effect which preoccupation with a single outcome ("academic achievement") has on the curriculum: Teachers reject more broadly based curricula because the effects will not show up in the assessments of their pupils and therefore themselves. In other words, the process leads to the elimination of the kinds of ecological environment which would have nurtured those talents. This results in the virtual disappearance of those talents. This results in a heightened belief that the only factor differentiating pupils one from another is "academic ability." This leads to more being done to increase scores. This leads to a proliferation of "qualified" job applicants. This leads to raising the bar to entry. Everyone has to run harder to stay in the same place. But then Ceci and Papierno, failing to note the norm referenced nature of the selection process, conclude that there will be more brilliant scientists. But note this. Whether or not it is true, all scientists will have been still more effectively inculcated into an image of reductionist science. They will be still more likely to undertake narrowly-based studies which ignore or fail to report other, possibly less desirable, processes and outcomes. If their scientific studies lie in the educational area, these will, in turn, recursively support the ever-narrowing activities going on in schools. If their scientific studies have to do with the application of physics, chemistry, or biology, they will fail to draw attention to, never mind study, the multiple effects of consuming energy, designing or marketing drugs, or the wider ecological effects of, 
for example, deploying marine based wind farms and marine turbines to harness the movements of the sea. ${ }^{20}$

In short, the Ceci and Papierno paper provides a nice illustration of the processes I am complaining about.

The only example I know of anyone taking the trouble to try to stem misleading applications of the results of their work in the educational area was Spearman around 1925.

As is well known, he demonstrated that there is, indeed, a conspicuous general factor running through the correlations between many "ability" tests and that this can be used to reduce the number of variables necessary to "explain" those correlations. But he went on, first, to emphasise that this does not mean that there is some underlying ability of "intelligence" - which he regarded as an extremely slippery concept. And then, in a number of extraordinary passages, went on to say that the tests that had yielded the correlations which supported his concept of $g$ "had no place in schools" because they distracted parents, pupils, teachers, and politicians from the business of education ... which is to "draw out" all pupils' talents. Furthermore, he wrote, "every normal man, woman, and child is a genius at something ... the problem is to identify at what ... this cannot be done with any of the psychometric procedures currently in use."

One cannot imagine any modern researcher including such remarks in the mandatory limitations of the study section of their reports. If government-funded it would be "more than their jobs worth."

Individualistic psychology

In psychology and society this neglect of context and systemic processes shows up as in a focus on the individual.

Among other things, it turns up as focus on "highly able people," "innovators," "leaders," "people with learning difficulties." 
But what we saw at Laneton* was that the apparent talents of the individual were largely determined by the context in which they worked and that they reciprocally affected that context.

Had our discussion been more complete, we would also have seen that the requisite change in the operation of the factory polluting the river was introduced, not as a result of a single intervention from an outstanding leader, but by multiple interventions at multiple points in a social system emerging from a climate of enterprise which was itself an emergent property of group activity.

More generally, as we saw earlier, the attribution of social problems to individual "cognitive deficits" has led to extraordinary state intervention in family affairs instead of to study of, and intervention into, the wider social processes associated with the existence and perpetuation of "areas of multiple deprivation."

Although it may seem something of a digression, it is actually important to note that this preoccupation with individual talents and dispositions in human beings shows up in our perceptions of the animal kingdom.

Popular television is pervaded by images of the benefits of competition in the wild without noting that such competition, taken to extremes, results in destruction of habitat and extinction of the group or species.

Instead of focussing on individual abilities and competition, those who made the programmes could have focussed on such things as meadows populated by hundreds of species of grass all living in symbiotic relationships with tens of thousands of species of plants, animals, and other organisms. Or, as Darwin put it, to a bank in which "a thousand flowers bloom."

This preoccupation with the individual has led many people to interpret Darwin's work as demonstrating the "survival of

* A collective name given to the schools in which the project work described earlier was carried out. 
the fittest." What it actually implies is the survival of the fitting: survival of the species who adapt best to the changing situation in which they find themselves.

This notion of the survival of the fittest emerges in society as pervasive brutal imposition of Social Darwinism on schools, "benefits" systems, and organisations.

It emerges as "educational Olympics" within and between schools: Olympics which have few winners but thousands of losers.

In organisations and society it results in the promotion of hierarchical, as distinct from organic, forms of management which are destructive of most of those who live and work in them and the environments in which they are situated.

These things must, at least in part, be viewed as arising from the criminal misapplication of "science."

And so we come to the conclusion that we urgently need to embrace, and guide our work by reference to, an alternative image of the nature of "science."

\section{NEGLECT OF SYSTEMS THINKING}

\section{Parents, Teachers, and Children}

In the course of my review of the literature relating to closing one kind gap or another I found few broadly-based studies of the ways in which parents and children recursively affect each other and in turn interact with the differential "demands" created by living with different kinds of peers in different types of community. ${ }^{21}$

I have to admit that I was sensitised to this issue by what we had found in the course of evaluating what was intended to be a pre-school educational home visiting project designed to en- 
hance the role which parents played in their children's cognitive development (Raven, 1980 a).

In the course of what we described as an "illuminative" (Hamilton et al., 1977). E evaluation ... which I elsewhere ironically characterised as "an evaluation which did not come up to standard" (Raven, 1997) ... we explored mothers' perceptions of the situation in which they found themselves and their goals and philosophy in child rearing in what might loosely be termed an open-ended sort of a way.

Well. That was a step in the right direction. But note this: To explore this "obvious" issue more thoroughly it would be necessary to get inside people's homes and heads to explore what was going on.

It would be necessary to largely abandon those rating "scales" of home environment the construction of which has largely been tailored to the conventional wisdom about "cognitive development."

We found mothers tailored their activities differentially to their different children and responded differently to differential feedback from those children. They facilitated the development of diverse competencies in their children by harnessing those children's particular motives. Many "working class" mothers were not preoccupied in the way middle class children were with the so-called "cognitive abilities" of their children-indeed in many cases they were actively opposed to them. And they related what they were doing to the demands of the conditions of life and areas in which they lived. (Being "strong and tough" and obeying parental commands without question was, for example, more important in "areas of multiple deprivation" than in "middle class" communities.)

So, although the conclusions to be drawn out of this example for the dominant image of "science" and its methodology are pretty obvious, it is worth again drawing attention to just how out of kilter they are with the dominant image of science as a process 
dominated by "measurement" "scales" and multiple-regression equations.

\section{The case of illiteracy}

Turning now to another illustration of the problems which arise from embracing reductionist science, I will now argue that the problems associated with illiteracy are largely generated by the system in which children live - and adults work - and not by deficits in the individual.

"Dyslexia" is a rag bag category encompassing a whole range of very different problems (Elliot \& Grigorienko, 2014) which might possibly need to be remediated and which, if they do need to be remediated, remediated in different ways.

But, more importantly, "it" mainly becomes a problem because the educational system fails to nurture and recognise the wide variety of talents pupils possess and nurture those talents in such a way that the "reading" problems pale into insignificance.

Although in some sense it trivialises the issue I am trying to raise here, we may note that "reading ability" is itself mainly assessed in, largely invalid, ${ }^{22}$ ways which fail to recognise the value of a wide variety of types of reading.

And the kind of reading that is assessed is that favoured and used by the middle classes in society.

And this leads to a circular systems problem.

Middle class bureaucrats occupy themselves writing manuals and prescriptions to determine what everyone from those who dig holes in the street through teachers and social workers to nurses and doctors shall do. (We may note in passing that, in this way they destroy the very professionalism that is most needed in these groups.).

And then they require everyone to take written tests to determine their knowledge of these prescriptions and regulations even though these have little bearing on the competence of those concerned. 
So those who do not read in the standard way are made to suffer for it by being forced to attend "remedial"(Raven, 2014) programmes which don't work but do prevent them engaging in activities which would help them to gain recognition for, develop, and utilise other important talents.

Systemic problems in the overall operation of the "educational" system

I return now to investigations into the workings of the educational system as a whole to illustrate that

the multiple "causes" of problems often do not operate independently but form self-reinforcing and self-extending systems which operate to negate the effects of single-factor interventions.

There are many reasons why schools neglect their main goals. These include: the fact that the main function of the system is not to educate but to legitimise, and assign position within, a hierarchical society; the fact that few understand how to nurture multiple talents; and the fact that there are no agreed means of giving teachers or pupils credit for having achieved what are agreed to be the main goals of the system.

But the most important conclusion we drew out of the work that lay behind these conclusions was that these factors do not act independently but form a network, or system, of recursive, and mutually supportive, feedback loops which collectively serve to negate the effects of single-factor, well-intentioned, intervention. ${ }^{23}$

What is more, the network seems to have a capacity to perpetuate, even extend and elaborate, itself.

This overall network is sketched in the following systemogram, an enlargeable version of which is available at http:/ / eyeonsociety.co.uk/resources/Figure\%201\%20\%28formerly\%2023.1\%29\%20rev.pdf. 
SOME ABUSES OF "SCIENCE," LOGIC, AND AUTHORITY...

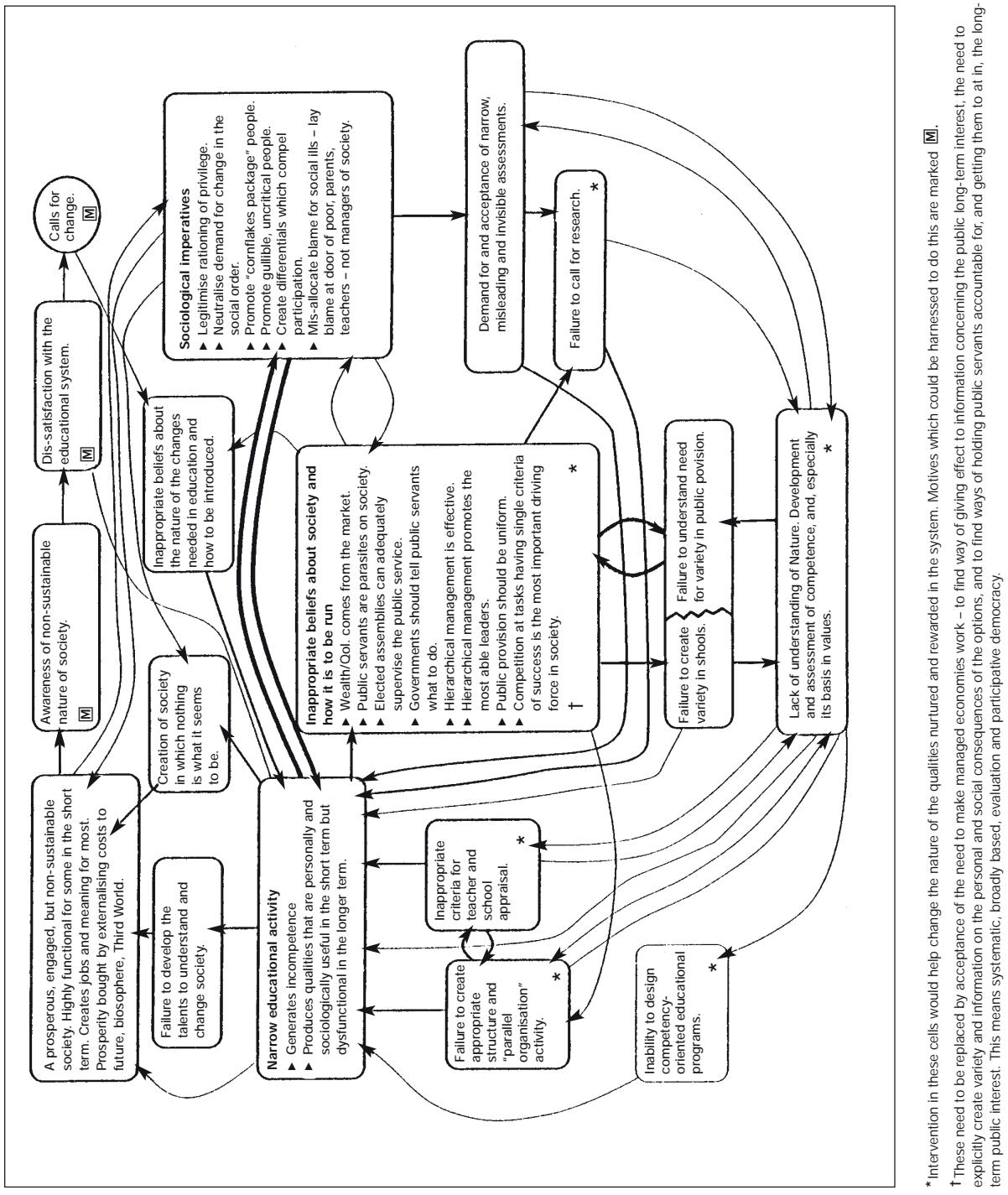

Figure 2. Feedback Loops Driving Down Quality of Education. 
This systemogram actually illustrates very many important things which cannot be discussed here (Raven 1994, 2012a, 2018a).

Here, it is sufficient to use the diagram to hint at the way in which multiple social processes interact with, and support, each other.

Few of the studies in the literature, still less policy pronouncements, give any hint of an awareness of such processes although they are, in reality, extremely common in the biological and social world.

Yet, unless they are taken into account, most of the studies purporting to investigate causal relationships are without foundation. And they call into question the blind application of multiple regression techniques in an attempt to investigate relationships and reveal a hidden causal world..$^{24}$

\section{The need to turn psychology inside out}

But there is one more, extremely disturbing, new insight to be drawn out of the diagram:

It is necessary to de-indivdualise explanations of human behaviour; indeed, it is necessary to turn psychology inside out.

The diagram makes clear is that what happens is not determined by the wishes of any particular group of people but by the operation of the system itself. It follows that the widespread tendency to single out and blame parents, pupils, teachers, public servants, or politicians is inappropriate. Their behaviour is mainly determined by the system.

It is vital to generalise this observation: We need to fundamentally re-frame the way we think about the causation of behaviour in a way which parallels one of the transformations Newton introduced into physics. Before Newton, if objects moved or changed direction, it was because of their internal properties: they were animated. After Newton it was mainly because they were acted upon by a network of invisible external forces which could never- 
theless be mapped, measured, and harnessed. We need a similar transformation in the way we think about the causes of human behaviour.

In short, we now need to turn psychology inside-out in the way in which Newton turned physics inside out.

PROBLEMS ARISING FROM THE DOMINANT PSYCHOMETRIC MODEL

The failure to attend to systemic problems was not the only thing that came to trouble me as I reviewed the literature relating to closing the attainment gap.

Others stemmed from the failure to recognise the problems posed by the dominant psychometric model ${ }^{25}$ and the failure to seek an alternative.

We have seen that absence of agreed measures of progress toward, or away from, the main goals of education-the nurturance of self-confidence, creativity, critical thinking, and the ability to understand and intervene in the workings of organisations and society-contributes to the processes driving education out of schools and results in misleading, lopsided, and unethical "evaluations" of educational programmes and policies.

But the resolution of this problem is not simple.

Such qualities cannot be assessed via the type of scale favoured by psychometricians.

The problem is that creativity, persistence, and the ability to build up an understanding of organisations are all difficult and demanding activities which no one is going to engage in unless they are strongly motivated to engage in the activity.

So, if one wishes to "assess" them, one first has to find out what those motives might be. Our research suggests that possible motives are legion but, as Spearman pointed out more than a century ago, they cannot be identified using any of the psychometric procedures in current use. 
Then there is a second problem. Success in carrying out these activities is dependent on bringing to bear a number of cumulative and substitutable components of competence-such as the ability to anticipate obstacles, persuade other people to help, and persist-which themselves will not be engaged in except in relation to a task which the individual concerned is strongly motivated to undertake (whether that be inventing and producing a new product, putting people at ease, creating political mayhem, or gaining control of an organisation).

A two-stage (not a two-factor) measurement procedure is needed.

First one has to find out what the individual is strongly motivated to do.

And then, and only then, whether, in relation to that, the individual demonstrates such things as self-confidence, creativity, persistence, the ability to persuade others to help, and the ability to think. ${ }^{26}$

We have outlined this model in more detail in several places $^{27}$

but the most important thing that it is essential to note here is this way of thinking is at loggerheads with the way of thinking which lies behind traditional psychometric procedures.

PROBLEMS WITH THE CONCEPTUALISATION AND ASSESSMENT OF HOME AND SCHOOL ENVIRONMENTS

It is immediately obvious that community, home, school, and classroom environments have a dramatic effect on children's behaviour and the attitudes and values and the talents they develop.

But the way in which these environments and the processes through which they are to be related to individuals are to be conceptualised and studied has left a great deal to be desired. 
As we have seen, most parents are concerned about the development in their children of a much wider range of abilities and dispositions than those with which most psychologists and educational researchers in the past have been preoccupied.

The result has been that the range of scales used to assess home and school environments has become largely restricted to those presumed to be related to such things as school attainment and (constricted notions of) "cognitive development."

At classroom level one finds scales relating to such things as the number of times teachers ask pupils questions and the amount of homework set.

At a school level they become even more constricted, emerging as questions about what are best described as "administrative" variables-class sizes, setting, streaming and so on.

These measures seem unlikely to be related to the capacity of parents or teachers to release and nurture the range of highlevel competencies which are widely believed to constitute the main goals of education, never mind the capacity to nurture and recognise different talents in different children.

In this context it may be useful to introduce a concept we ourselves have found useful when thinking about, and organising material relating to, facilitating the development of competence in homes, schools, and workplaces.

This is the notion of a "developmental environment."

Key features of developmental environments include a tendency on the part of the parents, teachers, or managers concerned to recognise and nurture the diverse talents of their children or subordinates instead of, for example, introducing hierarchical selection procedures, trying to motivate those concerned with external reinforcements, and trying to teach prescribed content.

In developmental environments people are encouraged to do things they like doing and are good at ... whatever those things may be ... including things that are often considered anti-social... and, whilst doing these things, develop important components 
of competence like the ability to find the information one needs, learn from the effects of one's actions, persist, and gain the cooperation of others. ${ }^{28}$

Be that as it may, the main point to be made here is that there is little trace in the literature of effort having been made to conceptualise and investigate the processes which facilitate education ... the development and recognition of multiple talents.

When one comes to enquire into the ways in which such processes have been assumed to relate to outcomes one encounters what can only be described as an appalling mess.

There is virtually no discussion of the recursive processes whereby, for example, the way in which the characteristics of parents and children recursively determine the way they treat each other. Still less of the way in which parents anticipate that the demands of the environments in which they expect their children to have to survive and prosper determine the way they treat their children. And still less how the children's own insights into these matters determines their relationship with parents, schools, peers, and authorities.

I will return to this.

But first I would like to pursue another topic.

FAILURE TO ENGAGE IN CONCEPTUAL OR CRITICAL THINKING

We have seen that there seems to have been a widespread uncritical acceptance of mainstream ways of thinking in the research that has been conducted.

To me, this seems to reflect very badly on the competence of researchers and the educational system that has produced them.

Here I will pick out a few topics for specific mention. 
The unexamined use of word "education"

The word education means, and is perceived by most parents, teachers, pupils, and employers to involve, drawing out pupils' individual and particular talents.

Yet schools are mainly, as the word teaching implies, concerned with "putting in." 29

Put like that, it seems obvious that teaching and education are essentially incompatible processes!

\section{WOW}

The evaluation of "education" as "putting in" implies assessment of how effectively whatever it was intended to inculcate has stuck.

Education as "drawing out" implies the recognition, release, and development of diverse forms of competence-i.e. the enhancement of diversity. So its evaluation should imply finding out how effectively this has been done.

As we saw at Laneton, education as drawing out not only means facilitating the development of emergent competencies which can sometimes only be said to exist in the context of other people possessed of other emergent talents but also creating emergent climates of intelligence or enterprise which again recursively engage and nurture emergent talents in individuals.

The unexamined use of word "learning"

Not unrelated to the above, "learning" is mainly conceptualised as absorbing content.

As the word is typically used, it does not encompass such things as learning to adventure into the unknown, learning to lead, learning to create political turbulence, etc. and the perception and evaluation of programmes which do attempt to do these things (such as Revan's "action learning" [Revens, 1977]) and 
the few varieties of "progressive" or "project-based" education which do set out to achieve these goals ${ }^{30}$ ) are rapidly corrupted in such a way that they come to be perceived as alternative was of enabling people to lean stuff. ${ }^{31}$

How to promote "learning" narrowly conceptualised is the question with which most researchers have been preoccupied.

If an alternative is acknowledged at all it tends to be conceptualised as "learning to do" - and further degraded into acquiring "technical skills."

More specifically, the notion of competence which we initially introduced to emphasise the importance of the pro-active motivational component of effective behaviour has been corrupted back into knowledge of the knowledge, skills and attitudes that some authority believes are required to perform some designated activity $^{32}$ rather than the release of the components of competence required to undertake some activity which the individual concerned is somehow intrinsically motivated to carry out.

Failure to examine the construct validity of the tests and measures used

As I reviewed the literature I needed to read to write my original article I was surprised how rare it was to find anyone questioning whether the tests or indices that were used really measured the construct they were said to measure. ${ }^{33}$

Thus scores on school attainment tests were regularly misleadingly said to be, and treated as if they were, measures of "cognitive ability" - which is to say "the ability to think" - which they conspicuously are not (and which is itself a notion in need of further conceptual analysis).

Likewise, tests said to measure "reading ability," "scientific ability," and "mathematical ability" could rarely, if ever, be said to have construct validity in these terms.

To take one example, most tests of "reading ability" measure, at best, only one form of "reading" ability ... the ability to decode 
a string of words dealing with a topic of minimal interest to most readers and answer questions about its content.

There are no measures of such things as:

- the ability to understand written material without being able to de-code and articulate the words

- the capacity to allow strings of poorly articulated words to evoke imagery in which one can delight or which provoke emotion and action

- the capacity to skim material to find things that relate to one's purposes and skip the remainder

- the capacity to allow the material, without necessarily understanding it, to evoke new thoughts, emotions, or images

- the ability to use it find material that does relate to one's purposes even though the present material does not ... by, for example, following up lateral thoughts provoked by the material.

Yet, those who do not do well on the procrustean tests currently in use become widely known by teachers, parents, and peers alike as "failures" and subjected to what are often experienced as demeaning, degrading, and punitive "remedial" treatments.

Measures of "scientific ability" fail to measure the ability to problematize, find new material, invent alternative ways of thinking about things, collect evidence etc.

The conceptualisation, nurturance, and assessment of "mathematical" ability is, perhaps, the most horrifying of all, but I quail to embark on a discussion of this topic here.

At a different level, the tests that are presented as measures of such things as self-confidence, resilience, creativity and so on sent shudders down my spine for the simple reason that they take no account of the fact that all of these things are always in relation to something. Self-confidence in relation to putting people at ease? In relation to passing school exams? In relation to creating social turbulence? Creativity in relation to what? Creating chaos in the classroom? Using writing to evoke emotions? And so on. 
This is not the place to discuss the problems with such tests in any detail or offer possible solutions.

My point is that most researchers seemed to accept the notion that the tests they were using were somehow valid measures of the constructs deployed in the discussion of the results and often used as a basis for policy actions.

They did not seem to see themselves as having a scientific responsibility to examine such basic issues.

\section{DEFICITS IN LOGIC}

If failure to discuss many of the issues raised above was disturbing, the effects of basic failures in logic (and therefore my assessment of the competence of researchers, public servants, and politicians involved) were frightening.

Here are a few examples.

The classical error of reasoning from correlation to cause

The literature is permeated with examples of the classical logical error of leaping from the observation of a correlation to the belief that the relationship is causal.

And then to the prescription of some intervention.

Example 1: If everyone gets more education, everyone will get jobs

This is based on the observed correlation between educational attainment and whether or not people get jobs.

The illogical nature of the conclusion-essentially that if everyone gets more education everyone will get jobs (although it is rarely stated so baldly)-stems from failure to recognise that both are norm-referenced variables. 
If one person's scores go up another's must go down. Unless the structure of society changes, if one person gets a job another does not. ${ }^{34}$

That is the way norm referencing works. By definition.

The relationship persists even if everyone gets more education.

What then happens is that everyone stays in the system longer (admittedly thereby lowering national levels of unemployment by keeping people out of the job market and creating jobs in the educational system [taken as a whole to include publishers and evaluators] itself) and employers raise entry requirements regardless of whether there is any change in the competencies actually required to do the jobs well (which there usually is not).

Yet belief that the relationship is causal has a whole series of systemic consequences.

Expressed as a belief that it is "vital to get those test scores up"(Ofsted, 2017) it results in

- horrendous narrowing of the curriculum,

- consignment of many to punitive remedial programmes which deprive people of leisure and opportunities to develop their other talents,

- gross interference in homes to compel parents to follow procedures prescribed for and by schools and believed to promote "cognitive development" and "academic" achievement,

- the introduction of armies of inspectors with extraordinary powers to intervene in homes and schools and punish (even via punitive "remediation" and compulsory re-education programmes) pupils, parents, teachers and head teachers alike,

- academic Olympics within and between schools and countries-Olympics which result in such things as

- invention of ways of excluding low ability students from testing programmes as schools seek high ratings,

- geographical migration of parents,

- cheating on tests, 
- falsification of statistics by head teachers, bureaucrats, and politicians.

Because of the norm-referenced nature of these tests, these Olympics necessarily have few winners but millions of losers.

The process is best described and understood as the brutal imposition of Social Darwinism

It is the first step in a process whereby the favoured few are showered with accolades while the losers are left to rot in backwaters of the educational system and in disadvantaged communities where they are subjected to punitive inquisitions and demands for compliance with destructive regulations if they are to obtain minimal income or health care "benefits."

Combined with other social processes, such as the financialisation of the economic system, ${ }^{35}$ the process results in the deeply divided society that so many have become so concerned about.

Example 2: Parental behaviour determines both their children's cognitive development and the problems their children they pose for schools and the community

Tens of thousands of studies have reported relationships between aspects of parental behaviour and aspects of child behaviour, especially "cognitive ability."

For many years it was assumed that the former caused the latter. What could be more obvious?

But when Rich Harris (2006) and others set out to investigate the way the observed relationships come about it emerged that it is mainly the variance in children's behaviour which leads to the variance in parents' behaviour.

But even such a statement is grossly misleading because the relationship actually stems from recursive interactions between parents, children, peers, schools, and community. 
And even that is a gross over-simplification dependent on singling out particular variables and behaviour for attention: Why is failure to attend schools that are often destructive of the particular student's talents and the problems stemming from its punitive remediation viewed as an issue demanding so much attention?

Re-focussing the discussion would require a dramatic change in many people's preoccupations and research methodology.

\section{Example 3: The effects of "remedial" intervention}

Many researchers have demonstrated that "remedial" programmes targeted at "those with special needs" (marginally) improve their scores on norm-referenced tests and, as a result, enable some pupils to move out of special needs classes and into classes where they are taught the regular curriculum.

What these researchers have failed to notice is, in effect, that the seats those pupils occupied were not left empty but were filled by other students.

Yet that is the way norm-referenced systems work.

Apart from any genuine gains in competence that may have been achieved (which are hard to measure and, as a number of researchers have shown, few in number) when all children are included in the evaluation the overall benefits are zero (Jope, 1984; Maxwell, 1996; Woolf, 1987).

\section{Example 4: Test scores at Time 1 predict scores at Time 2}

Researcher after researcher has been satisfied to interpret the correlation between children's test scores early in life with those same children's scores five or more years later to mean that the first causes the second and concluded that intervention early in life-especially with the "less able" or those from certain backgrounds-will collapse the variance and reduce the correlation. 
Quite apart from the fact that, as I show in Problems with "Closing the Gap" Philosophy and Research, there is not only no evidence to support these assertions but plenty of evidence to the contrary, what we should be most concerned about here is the widespread failure to question the logic of such assertions; the failure to demand an elucidation of the ways in which the observed correlation may come about. ${ }^{36}$

MORE SPECIFIC METHODOLOGICAL DEFICITS

Failure to investigate what else may have been (unintentionally) varied alongside the "experimental" variable the effects of which were supposedly being investigated

Again this is a recurrent error.

For example, in experimental studies:

- The schools and teachers involved may somehow have been selected on the basis of some non-specified criterion or led to believe that they are somehow special.

- The experimental variations on which attention has focussed may bring with them seemingly extraneous things like visits from interested researchers or inspectors;

- Components of the interventions may be experienced differently in different types of home or community-sometimes being experienced by some as very intrusive.

Then again, interventions may have different effects on different people in different social contexts. Some people may react in one way, others in another. Such differential reactions are well documented in some studies of the effects of psychotherapy where people react to "the same" intervention in very different ways, many of which are unlikely to be picked up using an arbitrary selection of off-the shelf tests. To document them one may need 
to tailor the measures used to the particular individuals on the basis of a prior comprehensive understanding of the workings of the system.

In cross-cultural studies aspects of the culture other than, for example, the curriculum processes under investigation may differ.

All of these things have major implications for methodology and the conduct of science.

They mean that it is necessary to have built up an understanding of the whole process before embarking on any kind of "statistical" study.

Yet it is rare to find any time or resources budged for such work: It is assumed that the nature of the problem and the methodology to be used to investigate it are already well understood by those in authority and all that is required is to carry out the work.

Failure to challenge the image of science, derived from a nodding acquaintance with the prestigeful field of physics, which implies that "science" has primarily to do with capturing the relationships between "variables" $(x$ and $y$ ) in some kind of formula (hence the proliferation of studies based on multiple regression models).

Yet this way of thinking is not, in fact, the dominant model in science.

It may be contrasted with the deployment of biological descriptions of plants and animals derived from a branching set of descriptors on the one hand and ecological descriptions of the interactions between these species and their habitats via endless symbiotic arrangements on the other. (As has been mentioned, a single meadow contains thousands of different species of grass living in symbiotic relationships with other plants and animals.)

As has been shown, we have deployed this alternative way of thinking about individual differences and their interactions with ecological habitat in our studies of environmentally-based project 
work in primary schools. And it has been given a boost through the work of Mottus. ${ }^{37}$

Failure to challenge the attempt to capture individual differences via scores on general traits

Creativity, "executive functions" (ability stay focused on the task, ability to organise etc.), persistence, and most other important qualities are conceptualised as general dispositions instead of characteristics which, as we have seen, in a sense, only exist when people are engaged in personally motivating activities.

The implications of this error are not limited to the measurement field. It also has dramatic effects on teaching itself.

For example,

- "Critical thinking" is seen as something which can be taught and measured independently of context.

- "Systems thinking" is conceptualised as a generalizable disposition which can, and should, be "taught" independently of context despite the fact that (i) most people engage in it in relation to some aspects of their daily lives and (ii) if effectively nurtured, it presents a direct challenge to both reductionist science and the authoritarian organisation of schools.*

* It has become fashionable to advocate the teaching of systems thinking in schools. This can mean many different things. But one stream of thought leading to its advocacy has to do with the need to consider the negative as well as the positive outcomes of burning fossil fuels-although, ironically, the outcomes considered actually get reduced to a single outcome (climate change) in most of the debate that has followed. And the need to find ways of intervening in the network of social forces which promote this process has again all too often reduced to proposed single-factor inputs, e.g. "reduce $\mathrm{CO}_{2}$ emissions." The need to promote systemic, i.e. non-reductionist, thinking is all too apparent.

But note what happens if one takes the task of promoting (not "teaching") systems/systemic thinking in schools seriously. One finds oneself in conflict with the image of science that has been imbued the thinking of science teachers 
In reality, as we have seen all of these qualities, like the "ability to think," are difficult and demanding activities which require the individual concerned to bring to bear numerous components of competence and thus demand the engagement of the individual's specific motivational dispositions before one can begin to make any meaningful statement about the individual's capacity to engage in them.

Actually one may conclude from these observations that, rather than seeking to "assess" them, it is more important to ask

- What does this person they tend to think about?

- In relation to what kinds of activity is he or she creative?

- In relation to what kinds of activity does he or she tend to engage in systems thinking?

... and so on.

And then, perhaps, "how can he or she be helped to think more creatively or systemically about those things ... or other things?"

Failure to move beyond the preoccupations in the literature.

Not only have the problems investigated been mainly determined by whatever it has been fashionable to talk and write about at the time, the way of thinking about those problems has been typically overwhelmingly determined by what is in the literature. There has been little attempt to introduce fresh perspectives.

and is embedded in the curriculum and examinations process. And one finds oneself in conflict with politicians.

Interestingly enough, the processes of systemic-i.e. multi-pronged-intervention actually needed to yield systemic change was nicely illustrated in the previously mentioned environmentally-based project conducted by primary school pupils. The process facilitated the emergence of new competencies in the pupils ... competencies which, in a sense, could not have existed outwith that context. But it also facilitated the emergence of a climate of enterprise going far beyond the talents of individuals. And it was the harnessing of that very climate of initiative and all those emergent talents that made possible the systemic, multi-pronged, intervention that achieved the desired effect. 
The problem is that to do these things in a meaningful or systematic way it would be necessary to channel funds to mavericks; to fund adventurers the outcome of whose work cannot be specified in advance.

This, in turn, would make it necessary, to use a non-PC, but catchy, phrase to "fund the man and not the plan"; to channel funds to people who are likely to come up with some new insights even if those insights were not envisaged at the start ... and not to people who are able to generate proposals which hit all the right notes among those with a stake in the existing thinking.

Such a way of thinking is at loggerheads with the dominant framework of thinking about how research should be funded.

PROFESSIONAL FAILURES

So far, I have focussed mainly on the scientific errors which have contributed to the accumulation of mountains of misleading, and often destructive, information.

I turn now to what may be considered to be professional failures to take action to stem this process. I am afraid there is rather a long list of these.

Failure to contextualise one's work, i.e. failure to spell out its limitations when viewed in a context of systemic science. (Spearman's contextualisation of his work on " $\mathrm{g}$ " offers an illustration of what could be done more often.)

Failure to discuss the ethical -i.e. unintended, multiple, and social-i.e. scientifically demonstrable - implications of implementing conclusions based on what is presented as objective and value-free science.

Failure to challenge sponsors' framing and definitions of the problems to be investigated by setting them in context. 
More specifically, failure to recognise, and intervene in, the circular process whereby the framing of problems leads to unprofessional studies which support that definition i.e. failure to recognise and intervene in the process whereby one gets policy-based evidence instead of evidence-based policy.

Failure to persistently ask "Who is the 'Customer'?" in relation to government-funded research conducted on the basis of the customercontractor principle.

Failure to challenge the limitations of job descriptions issued by "authorities."

More specifically, failure to insist that behaving as a professional implies going beyond those job descriptions.

Failure to discuss what it means to be a professional. ${ }^{38}$

Failure to challenge politicians' implementation of policies based on their own interpretations of the implications of whatever studies they can lay their hands on to support their viewpoints.

Failure to call attention to, and challenge, the pervasive implicit assumption that the objective of much policy-based research is to generate "teacher-proof"- or "idiot-proof" - (manualised) prescriptions for how teachers and others involved in providing services should behave. The alternative would be to nurture the professionalism of teachers and others providing services and their ability to respond in different ways to different situations. ${ }^{39}$

Failure to appreciate, and promote recognition of, the fact that the incorporation of single-factor thinking into policy-making inhibits any tendency to set up a variety of experiments to cater for people who 
have different priorities to one's own and to assess the effects of those alternative policies.

Failure to challenge the notion that competition between those tendering to provide services yields the most cost effective services. Following through with the "dyslexia" example, prospective providers are asked to tender for providing services that will nominally fix the rag bag set of problems that are so categorised (Elliot \& Gregorienko, 2014). For this process to work, it has to be assumed that all will require approximately "the same" treatment-otherwise it would not make sense to compare tenders. Nothing could be further than the truth - and the most effective "treatments" would require reform of the "educational" system itself.

The problem is even clearer in the health service where commissioners require prospective providers to tender for providing pre-specified (and unevaluated) services at a series of points as patients move along pre-specified "paths." As Seddon (2008) has shown, precisely because they are not tailored to the patient's particular needs, these rarely work. The result is that patients re-present with the same symptoms and complaints as they had at the beginning of the process. This greatly inflates the apparent demand for the ineffective service ... Seddon calls it "Failure demand."

Failure to resist the temptation to seek impose (by force if necessary) that which one believes to be good and right on others "for their own good and society as a whole" regardless of its multiple consequences for those concerned and society as a whole-i.e. failure to resist what appears to be a pervasive disposition to fascism. ${ }^{40}$ As Roberts (2018 a; b) and I (Raven 1980b, 2018b) have shown, this process is glaringly obvious to those who have eyes to see in the social media, the imposition of notions associated with Political Correctness, the workings of the Parliamentary enquiry 
into the effects of the ever-more-inclusive concepts of adverse childhood experiences (ACEs) ${ }^{41}$ and the ever-widening concept of "vulnerability" - all of which bring with them an apparent "need" for authoritarian intervention everywhere and in everything to restrain others from Politically Incorrect behaviours.

Failure to support mavericks and whistle-blowers who call attention to unwelcome implications of some studies, deficits in others, and deficits and unwelcome implications of current arrangements in provision.

\section{ABUSES OF AUTHORITY}

As I see it, what is in effect the criminal misuse of authority occurs in the:

- Constriction of university research funding (acquisition of which is almost a prerequisite to advancement in academe) mainly to that available by responding to government "calls for proposals" to undertake tightly prescribed and monitored research under contractual arrangements which, among other things, prohibit enquiry into issues not specified in the call for proposals (thereby eliminating the traditional role of the university - which was to engage in free-ranging enquiry (Weerts, 2016). ${ }^{42}$

- Insistence that any publications arising from research conducted on a "customer-contractor" basis should first be approved by government.

- Inclusion of a right to actually alter figures in the reported results of such research.

- The elimination of academics' time to think via pressures generated through Research Assessment Exercises (Research Excellence Frameworks). 
- Constriction of research to small scale and experimental studies instead of embracing wider issues. (The processes whereby this comes about are discussed in more detail in a separate paper. ${ }^{43}$ Here it is sufficient to note that small, non-threatening, studies are easier to progress through the research-funding, $\mathrm{PhD}$-generating, and publication process that has been imposed upon, and come to be accepted by, the Universities).

- Elimination of challenge to narrow and conventional perspectives via a mandatory peer-review process (which operates to eliminate papers which challenge to the conventional wisdom) as required for publication in "high impact" journals to satisfy the requirements of the Research Excellence Framework.

- Enforcement of commands to attend school (even though that process may be highly destructive) via an army of enforcement officers targeting both pupils directly and their parents.

- Introduction of mandatory curricula concentrating on imparting and testing narrow snippets of irrelevant knowledge and thereby enforcing the neglect of the wider competence goals educators could potentially pursue ... and following through into imposing this framework even on Home Educators.

- Imposition of mandatory national testing programmes at regular intervals (to reinforce pupils' knowledge of their true status in the pecking order ${ }^{44}$ ) using norm-referenced tests constructed according to principles of dubious merit.

- Using the results of these tests to orchestrate Educational Olympics within classrooms, between schools, and between countries ... Olympics which, as in Social Darwinism more generally, have few winners but millions of individual and collective losers.

- Introduction of armies of inspectors with extraordinary powers to intervene in homes and schools and punish (even via punitive "remediation" often involving giving up otherwise free time) pupils, parents, teachers and head teachers alike. 
- Mandatory bureaucratic generation of rules and manuals of procedure to control and prescribe the behaviour of children, parents, teachers, and social workers ... all coupled with the generation of training programmes to teach all concerned the rules embedded in the Manuals. In short, mandatory destruction of professionalism.

- Requirements to seek tenders for providing centrally-specified, assumed to be routine, services-a process known as "commissioning" in the Health Service-when, as discussed above, what is required is a range professionally-generated client- and situation- specific services tailored to those needs and situations.

- The centralised stetting targets (test scores; time to achieve specified outcomes; number of pupils enrolled etc.) the achievement of which deflect the attention of those concerned from the goals of the system.

- Mandatory intervention in homes to impose values and behaviours which may be foreign to the parents and families concerned and ill-suited to the communities in which people live.

- Mandatory infringements of human rights via data sharing (health, crime, income, home environment assessments) among armies of inquisitors.

- Removal of children and parents from homes and replacement by regimes of care (personal or institutional) which often turn out to be anything but caring (McKnight, 1995).

- Corruption of rights (eg to education, life, leisure and happiness [well-being]) into requirements (eg to attend schools (however bad); to provide specific types of home environment; to display "appropriate attitudes toward own sexuality"; etc.) accompanied by heavy-handed monitoring followed by punitive sanctions. 
At this point, it is perhaps appropriate to, once again, underline the pervasive influence of neo-liberal thoughtways-i.e. the belief that what is important for social survival is competitive success at tasks defined by some authority and therefore bringing with them a moral duty of compliance. (Tasks often defined in this way include gaining an income, doing well in school, and avoiding dependence on the health and "welfare" services.)

The source of the belief that one has the right to impose on others, by force if necessary, thoughts and behaviours that one believes to be good and right regardless of the consequences for those individuals and society, and the implied denial of the right and the ability of individuals to take decisions for themselvesi.e. fascism (spelt with a lower-case " $\mathrm{f}$ ") — merits the most urgent and serious investigation. ${ }^{45}$

HOW HAS ALL THIS COME ABOUT?

Given that we have now seen that the field is permeated by unscientific, unjustifiable, and misleading studies, many of which have destructive consequences, and a widespread failure to behave in a professional manner, one must ask how all this comes about.

I found that I had written a long (4-page) section on this topic.

Unfortunately, on reading it over, I found that, while it offered a more detailed explanation of how the customer-contractor principle comes to exert such control over educational research than has so far been offered, it gave little insight into the processes whereby non-systemic, reductionist, science has become so embedded in our thoughtways or how it comes about that the hierarchical authoritarian thoughtways of Social Darwinism have come to be imposed on society under the guise of "NeoLiberalism." 
I have therefore relegated this material to an Appendix ${ }^{46}$ which should become available on my eyeonsociety website www.eyeonsociety.co.uk

Generating an explanation of the more basic issues mentioned at the end of the penultimate paragraph would involve a major research effort.

I have to confess that I myself flip between explanations grounded in terms of "psychological" characteristics of the kind brought together in my note entitled "undesirable human traits"(Raven, 2006b) and explanations grounded in situational constraints (networks of social forces ${ }^{47}$ ).

Nevertheless, despite the possibility of finding a sociocybernetic explanation, it does seem to me, from the evidence currently available, that, behind many of our problems lies a pervasive human predisposition to believe that one has right to impose, by force if necessary, whatever one believes to be good and right on others regardless of the consequences for those concerned and, indeed, society generally ... with its inevitable recursive feedback onto the individual concerned.

This predisposition seems to extend to a frightening willingness to condemn and ostracise people with other values who make themselves visible through the social media, and, not necessarily more seriously, a historical willingness to assign others to concentration camps, to elaborate more effective ways of torturing them, and to burn those who hold "inappropriate" political or religious beliefs at stake.

It is tempting to believe that the latter are things of the past. But one sees the same process at work in the willingness to support, participate in implementing, and even personally elaborate, destructive components of "educational" and "welfare" policy. ${ }^{48,49}$

It also extends to pervasive acceptance of the notion that it is appropriate in a democracy to take decisions which are binding on all despite the variation in opinion and the inappropriateness of the proposed actions (Raven, 1980b). Indeed the essence of "de- 
mocracy" is largely seen as inhering in the voting process which enables the values of those who shout loudest to be imposed on others rather than in a process which would lead to decisions which would enable people who have different priorities to lead their lives in their own way.

While it is true that so-called neo-liberal policies are usually, perhaps invariably, backed by force ... meaning, in the case of economic policies (Klein, 2007), the army and, in the case of schooling, threats of having children taken away, consignment to remedial re-education programmes, and imprisonment ... the hegemony of neo-liberal thoughtways perhaps plays a much more important role. ${ }^{50}$ These inform policy in almost every domain.

If there is any truth in my suggestion that many of these things are to be attributed to what one might call a series of undesirable human traits (Raven, 2006b) it raises serious questions for psychological research ${ }^{51}$ into the nature of these dispositions, their effects, and what can be done about them.

\section{CONCLUSIONS}

At this point it seems desirable to attempt to draw out some of the insights which have emerged in the course of this essay as a basis for a discussion of how to move forward.

I will present them as a bulleted list.

- The mountain of misleading and destructive misinformation that has emerged from the "scientific" community is vastly greater than that brought to light by the "replication crisis."

- The blind pursuit of non-systemic, reductionist, science has brought the planet as we know it to the brink of collapse. It is vital to halt the process.

- It is essential to question the application of the word "objective" to most of the studies that are presented as "scientific" 
and objective research that can be used as a basis for "evidencebased" policy.

- It is urgent to publicise the fact that, as a result of the way most current research is funded, most of what is presented as contributions to "evidence-based policy" is to be understood as "policy-based evidence" and to be treated with profound scepticism

- It is necessary to further clarify and expose the network of social forces which lead to the publication of hundreds of thousands of studies which do not replicate and drive the conduct of major studies in such a way that they generate unscientific and misleading information which is nevertheless presented as information to be used as a basis for "evidence-based policy."

- Despite the need for a better understanding of these processes, it is immediately obvious that it is essential to break the stranglehold which the "customer-contractor" principle exerts over the issues which get researched, the way they are investigated, and the ways in which they are reported.

- There is an urgent need to insist upon comprehensive evaluation in evaluation studies. Comprehensive evaluation implies an attempt to document all short and long term, personal and social, desired and desirable, and undesired and undesirable effects of whatever is being evaluated for different sorts of people and in different contexts.

- There is an urgent need to challenge the criteria typically applied when assessing the quality of evaluation studies. Contrary to common assumptions, it is more important to get a rough fix on all outcomes than to get an accurate fix on any one of them.

- It is necessary to focus the attention of educators' and psychologists' on the objectives of education (viz. to "draw out" all pupils' individual talents) instead of on the objective of teaching-which is to "put information into" the heads of pupils. 
- It is necessary to "de-individualise" the image of science as a process which is primarily concerned with seeking to document the relationship between one dependent and one independent variable at a time and replace it by one in which the guiding philosophy is to seek out and study the multiple and recursive feedback loops that are involved in any relationship.

- More specifically, it is necessary to de-individualise psychology ... to move from a preoccupation with the individual toward a greater concern with emergent group characteristics and the role which external social forces and social context play in the determination of behaviour.

- It is necessary to promote a radical change in the latent image of "science" which guides most research in psychology from what might be called a "physics-based" image to one drawing on an image of research and thinking in biology and ecology.

- It is necessary to respect, and appreciate the value of, diversity in society instead of appearing to value mainly "gifted," "talented," or in other ways "outstanding" individuals.

- It is necessary to resist the, seemingly pervasive, (fascist) temptation, especially among politicians, to seek to impose what one believes to be good and right on others without regard for the values and wishes of those concerned or the wider and long term effects on society.

- There is an urgent need to generate ways of indexing a wider range of human talents.

- There is an urgent need for those who study the relationships which exist between parents, children, teachers, schools, and community to embrace a wider range of issues and adopt more appropriate methodologies.

- In that context, there is an urgent need to develop alternative ways of thinking about home, school, workplace, and societal environments. 
IMPLICATIONS FOR PROFESSIONAL ASSOCIATIONS

In the light of these conclusions, it would seem that it is vital for members of professional Associations, such as the Polish Psychological Association, to take an active role in promoting the kinds of change noted above.

It is unethical and unprofessional not to do so.

Unfortunately, as Roberts (2018a, b) and I (Raven, 1980) have noted, there is not merely a widespread reluctance to protestclaiming, not without reason, ${ }^{52}$ that it is "more than one's jobs worth" to do so-but, as we noted a little earlier, a pervasive tendency for many people at all levels in a wide range of "professions" from doctors through social workers and "benefits" administrators to managers in private sector organisations ${ }^{53}$ to go along with, and even personally elaborate, simplistic decrees which involve imposing others that which is deemed to be good and right regardless of the wishes of those at the receiving end or the wider consequences for those concerned and society ... with the inevitable recursive repercussions for the administering agent him or herself.

While we now attempt to distance ourselves from activities of this sort that resulted in imprisonment or death by associating them with the Nazis or religious crusades, the truth is that, as Webster (20014) and Butler (2015) have shown, such things are very much alive in the UK today. They show up particularly in the network of policies associated with the "benefit" sanctions and health care systems of the Department of Health and Pensions, the previously mentioned Scottish Children and Young Persons act and the impending policies associated with what are termed Adverse Childhood Experiences (ACEs). ${ }^{54}$

Is it not going too far to suggest that something of the same sort can be observed in the "educational" system with its network of statutory curricula and attendance officers? 
So I suppose my most basic recommendation must be to act as professionals: To challenge abuses and misrepresentations.

This will mean elaborating what it means to be a professional (Schon, 2001; Flynn, 2000).

As far as research is concerned, I suppose that the first thing to do is disseminate awareness of the huge range of topics that have been neglected and the failings in much existing research-but perhaps especially, the need to initiate research into the nature of the psychological processes which result in people feeling able to participate in the destructive processes discussed above.

But the truth is that the necessary developments cannot be introduced in the context of current arrangements for the funding, conduct, and evaluation of research.

Funding research via competitive responses to government "calls for proposals" to conduct research on a "customer-contractor" basis is particularly damaging.

It is vital that we make more effort, through our professional Associations, to challenge these and, in particular to place more emphasis on inducing politicians and public servants to seek ways of funding the kinds of research I have indicated. Especially adventurous research the outcomes of which cannot be pre-specified.

But, behind this actually lies a fundamental need to influence beliefs about how the processes of governance should work.

The need is to create a pervasive process of experimentation and evaluation especially in relation to generating variety and the opportunity to evolve different ways of living and working (Raven, 1993, 1994, 1995). Unfortunately, as I have shown elsewhere (Raven, 1980b, 2008, 2018a) there is a network of process which operate to inhibit such developments. Ironically, therefore, it would seem sensible to begin by studying these processes.

But research is not the only problem.

In connection with the previously mentioned, reality-based, reluctance to protest it is important to find ways of providing more security for whistle-blowers and mavericks. In saying this 
I mean to imply such things as creating a fund which will enable people's salaries etc. to be paid should they lose their jobs and their prospects.

On my website I make a number of other suggestions relating to ways in which it might be possible to intervene in the wider network of processes driving destructive behaviour (Raven, 2018b). Among these is a recommendation to insist on naming those at all levels who have been involved in the sequences of decisions which result in such negative outcomes. As John Stuart Mill (1859) emphasised, the best way to get people to act in the long term public interest is to make their behaviour visible to others. It may require legal action to force those involved to accept that their names will be associated with their actions and the consequences of those actions. Professional Associations could usefully promote the implementation of such legislation.

Then there is the possibility of traditional union-type activity to enable members to refuse to work under contractual conditions which lead to the production of misleading research and to the implementation of destructive policies.

One might also envisage the creation of a fund to support more adventurous research and, perhaps more specifically, research to understand the processes which lie behind the pervasive disposition to fascism and the brutal imposition of social Darwinism. ${ }^{55}$

\section{END NOTES}

1 Scottish Government (2014)

${ }^{2}$ Getting it Right for Every Child. (Better termed "Getting it Wrong for Every Child").

3 An acronym for the eight wellbeing domains indexed in the CfE Health and Wellbeing curriculum. It stands for Safe, Healthy, Achieving, Nurtured, Active, Respected, Responsible, Included.

4 This is not to say that there are not, as some of those interviewed by Graeber (2018) reveal, many others who personally resent the role into which 
they have been cast but feel that it is "more than their job's worth" to protest. As can be imagined, this leads many to leave their jobs leaving an ever-higher proportion who are willing to comply. (This process is also to be found among teachers.)

${ }^{5}$ Formal knowledge has a half-life of a year, i.e. people forget $50 \%$ after 1 year, $75 \%$ after $2,82.5 \%$ after $3 \ldots$ and so on.

${ }^{6}$ Few students enter employment in their area of speciality and, even if they do, they change jobs or the jobs change within two or three years. In any case, the knowledge that is required is a unique combination of up-to-date, largely tacit, knowledge.

7 Actually, there was more than one class but a composite picture has been generated for presentational purposes.

8 The notion that a system can have emergent properties of its own, not possessed by any of the individuals within it and, as such, have effects which no one within it intended will become a recurrent theme in this essay. Thus, as we shall see, a system can not only induce actions which run contrary to the espoused goals of those within it but even "feel" threatened, and take action to counter, moves to get it to perform its espoused, as distinct from latent, functions.

9 Again this is a composite picture generated for presentational purposes.

10 See also Raven (1980a, 2012a) for a description of the processes many parents employ in fostering competence in their children and Klemp, Munger \& Spencer (1977) for a description of the way in which some naval officers managed the development of individual and group competence in the US navy. Robinson \& Aronica's (2015) accounts of the transformations which some teachers have been able to effect in a number of schools also reflect this process.

11 One sees the exact same processes summarised here in the accounts of the way in which a number of dedicated and creative teachers were able to transform the work of some schools in the writings of Robinson \& Aronica (2015), in the studies my colleagues and I conducted in homes (Raven, 1980a), in secondary as well as primary schools (unpublished observations), in colleges ( $\mathrm{O}^{\prime}$ Reilly, Cunningham, \& Lester, 1999; Raven \& Stephenson, 2001; Winter, McClelland, \& Stewart, 1981), and workplaces (Klemp et al. 1977)—and, more generally, in among the "change masters" studied by Kanter (1985). As an aside we may note that, although Robinson focuses on the way in which the creative and confident teachers he describes were able to create environments in which multiple, highlevel, talents were nurtured, he does not draw attention to the competencies possessed by these outstanding change masters themselves. (In actual fact, he does little to clarify the components of the developmental environments they created in a form that would enable other would be change masters to do likewise.)

12 "Reward" often consists of an opportunity to do more of the same. 
13 See also the processes that take place in what Kanter (1985) has termed "parallel organisation activity" in organisations and briefly discussed below.

14 There is no real contradiction between the competencies they are trying to nurture and those required in workplaces and society (see Raven, 1997; Raven \& Stephenson, 2001) but there is a serious conflict between these and the assessment and selection procedures most widely employed in modern society.

${ }^{15}$ It is of more than passing interest to note that, in accounting for the achievements of the Finnish educational system, albeit largely measured in traditional terms, Sahlberg (2015) devotes most of his book to discussing changes in the wider social socio-economic-bureaucratic system within which the teachers worked.

${ }^{16}$ For some reason (which merits serious speculation), the final report prepared by the Task Force was never published. A set of recommendations for journal reviewers was, however, published by Wilkinson (1999).

17 Raven (2018c)

18 There are sure to be many small studies (which I did not review) that may escape this accusation.

19 However, this is not the only problem. Also important were the very same processes as those that have driven the production of hundreds of thousands of trivial and non-replicable "research" studies. These stem in part from the onerous requirements of government Research Evaluation Exercises and the Bergamo process. Also important are the recursive funding arrangements whereby politicians tend to frame problems in terms of a presenting problem and constrain research funding to topics which can be addressed in that context. But there is a wider "political" problem. Thus we find a dramatic drop in the number of studies which did attempt broadly based evaluations of educational policy (such as Goodlad's (1983) study A Place called School) with the arrival of Mrs. Thatcher in the UK and the imposition of a "customer-contractor" which was deliberately designed to frustrate wide-ranging fundamental research in the universities and research institutes.

${ }^{20}$ Yet even the effects of the electro-magnetic fields generated by the marine cables required to transmit electricity from the generators to land have dramatic effects on the feeding and breeding habits of the fish and micro-organisms in the sea who then have to travel miles to avoid them to reach their food and breeding grounds.

${ }^{21}$ That there were any at all is largely attributable to Harris's (2006) reversal of the previously widely accepted belief that parenting style overwhelmingly determines their children's "cognitive development."

${ }^{22}$ Clark (2014), Raven (1991, 1997, 2014), Suggate (2012). These measures have little predictive validity outside the educational system (Schmidt et al., 2016). The measurement of differential change (eg more vs less "academic" 
pupils) in response to some intervention is even more problematic (Kazdin, 2006; Prieler \& Raven, 2008).

23 This is actually an illustration of Forrester's (1971/1995) law which asserts that single factor intervention in poorly understood networks of social forces always has counterintuitive, and usually counterproductive, effects.

${ }^{24}$ To tell the truth, in reality, two, related branches of science have sprung up to relate to them: "socio-cybernetics" and Dynamic Systems Modelling. See http:/ /scio.org.uk/ for an organisation devoted to the former and http:// systemdynamics.org.uk/ for the latter.

${ }^{25}$ Lester (2001) has drawn attention to a fundamental deficit of that model even in the domain in which it is assumed to work. It is commonly assumed that it is somehow easy to assess knowledge even if the assessment of eg creativity is a problem. Nothing could be further from the truth. In fact it is virtually impossible to assess what a person knows! It is easy to find out if he or she knows something the assessor knows. But that is trivial. But the important knowledge a person has is largely idiosyncratic and tacit, i.e. non-verbalised and largely located in the heart and hands rather than the head.

${ }^{26}$ As an aside we may note that, instead of trying to assess an individual's level of creativity, internal locus of control, etc. in a generic way-across all possible motives, it makes more sense to reverse the question and ask in relation to what is this person confident, creative, persistent, thoughtful, and so on?

27 Raven (1997, 2014), Raven \& Stephenson, (2001)

${ }^{28}$ For a fuller discussion of the nature of developmental environments see Raven (2017) [main paper] or Raven (2001).

${ }^{29}$ Discussions of social policy are bedevilled by the use of words which have come to mean their opposites-see Raven (1997a).

30 See Note 6.19 in Managing Education (Raven, 1994) for a bleak review of the ways in which proponents of project-based education have presented their work.

31 Most of the teachers Bennett (1976) asked about "progressive education" saw it as an alternative way of achieving the standard goals, not as a process directed toward different goals.

${ }^{32}$ As a glance at the chapters making up Mulder's (2017) book will quickly reveal.

${ }^{33}$ A tiny, eg laboratory, measure was regularly treated as an index of a construct having wide generalisability.

${ }^{34}$ This is what is wrong with Ceci \& Papierno's (2005) claim that if, as a result of offering remedial educational programmes to everyone everyone's scores will go up and we will get more "outstanding scientists."

35 The phrase "financialisaion of the economic system" refers to the evolution of a class of people who make money out of trading in money rather than 
out of the production and distribution of goods and services. The generation of the requisite money has been facilitated by such things as the removal of controls over the activities of banks and the enaction of legislation facilitating the establishment of huge numbers of unregulated banks. Without wishing to minimise the role of a network of social forces in creating this situation one can nevertheless, with the aid of such publications as those of Klein (2007), discern the brutal imposition, by military force if necessary, of social Darwinism.

36 Bailey et al. (2018) have devoted a whole article to evidence supporting this claim.

37 Mottus \& Rozgonjuk (2019). See also Raven (2020).

38 See Schon (2001) for an important discussion of this issue. But see also Raven (2011).

${ }^{39}$ While I have used the material brought together in Hattie's meta-analysis to illustrate the mis-use of science, Hattie's own conclusions are remarkably different from those usually drawn: he demonstrates that it is teachers' ability to identify and invent ways of dealing with students' problems ... and show students how to do this-i.e. how to engage in the cyclical process of studying the effects of one's actions and take remedial action that constitutes the most important component of teacher competence. (Hence the sub-title "visible learning")

${ }^{40}$ (Political) banding together to promote a cause as represented in the symbol of a bound band of otherwise weak sticks-fascio in Italian-is only the last step in a process based on a particular agreement about what it is that should be imposed on others. In political terms this is usually agreement to impose a hierarchical "pure," clean, culture defined in moralistic or religious terms on others.

${ }^{41}$ Parliamentary enquiry into effects of adverse childhood experiences (ACE) (2018) https:/ / www.parliamentlive.tv/Event/Index/730b9508-5ff6-4464-a7b82bbb6f709ef5

${ }^{42}$ It is of more than passing interest to note that, in response to Mrs. Thatcher's request that he write a report which would help her to close the Social Science Research Council, Lord Rothschild (1982), while promoting the customer-contractor principle, both noted that social scientists were their own worst enemies because they embraced narrow academic studies and avoided wider and more socially important issues, also called for the budgeting of commissioned research to add 5\% of the research and development costs for scientist initiated research. Given that the development costs of many educational projects are huge, this would amount to an enormous sum of money.

43 Raven (2020, in preparation).

${ }^{44}$ Far from enhancing motivation to do "well," the effect of repeated testing on norm-referenced tests which, as an inevitable outcome of the scaling process used, define $50 \%$ of the population as failures is to precisely confirm many pupils' 
impression that they are indeed failures and in a positon from which they cannot escape no matter how hard they try.

${ }^{45}$ In this context attention may be drawn to the work of Fink (2016) and Roberts (2018b)

${ }^{46}$ Currently Non RPM conference papers: bps ed sect 2019 how come about. doc.

47 Such as those depicted in Figure 1 above and discussed more fully in Raven (1994, 1995, 2018a).

${ }^{48}$ Roberts (2018b) has argued that these play a major role in formulating the destructive and death-promoting policies which lie behind "benefits" sanctions, in support for those policies, and in the pervasive elaboration of those policies by those charged with enacting them. Webster (2014) had earlier documented the pervasiveness of the deeply destructive activities engendered by the benefits sanctions policy, and Butler (2015) had produced statistics on the number of actual deaths resulting from these policies. In the first 11 months of 2011, 1300 people deemed fit for work had died along with a further 7, 100 who had been allocated to support groups. And between December 2011 and February 2014 another 2380 died after having their claims for support rejected because they had been deemed fit to work. Many more had been driven to suicide because they were simultaneously deemed fit to work by one set of officials and denied job seekers allowance because they were unfit to work by another. The government has blocked access to later statistics.

${ }^{49}$ See Raven (2018b) for links to many examples of activities designed to suppress human rights.

50 As discussed below, in extreme form these express themselves as brutally social Darwinistic.

51 Roberts (2018b) and a great deal of earlier work relating to the disposition to authoritarianism and fascism.

52 See Nutt (2012) and letter from Narinda Kapur in the October 2018 issue of The Psychologist (Kapur, 2018).

53 There is a brief discussion of the ways in which a single firm-Unumorganised to make money out of the DWPs "work or die" benefits programme in Roberts (2018b).

${ }^{54}$ https://www.parliamentlive.tv/Event/Index/730b9508-5ff6-4464-a7b82bbb6f709ef5

55 As a student, 60 years ago, I studied the work of Adorno and FrenkelBrunswik on their " $\mathrm{F}$ " scale, but was shocked by the conflation of prejudice with statistically verifiable information on group differences. I am aware that there have been major developments in work on "authoritarianism" in the interim, but have not followed them in any detail. Nevertheless such work as I did read did not seem to engage very effectively with the issues I have been concerned with here. 


\section{REFERENCES}

Andersson, B-E. (2001). School is Good for Many, but Bad for Too Many. Voices from Students About Their School Situation. Mimeographed paper. Stockholm: Institute of Education, Department of Child and Youth Studies

Bailey, D. H., Duncan, G. J., Watts, T., Clements, D. H., \& Sarama, J. (2018). Risky business: Correlation and causation in longitudinal studies of skill development. American Psychologist, 73, 81-94. http://dx.doi.org/10.1037/ amp0000146

Bennett, N. (1976). Teaching Styles and Pupil Progress. London: Open Books.

Butler, P. (2015). Thousands have died after being found fit for work, DWP figures show. The Guardian (August 27). Retrieved June 6, 2015 from http:/ / www.theguardian.com/society/2015/aug/27/thousands-died-after-fit-forwork-assessment-dwp-figures

Campbell, D. T. (1979). Assessing the impact of planned social change. Evaluation and Program Planning, 2(1), 67-90.

Ceci, S. J. \& Papierno, P. B (2005). The rhetoric and reality of gap closing: When the "have-nots" gain but the "haves" gain even more. American Psychologist, 60, 149-160.

Clark, M. M. (2015). The effect of the phonics check on young children's ideas about written language. Why should we be concerned. The Psychology of Education Review, 39 (1, Spring ).

Elliott, J. G., \& Grigorenko, E. L. (2014). The Dyslexia Debate. Cambridge, UK: Cambridge University Press.

Fink, B. (2016). How Neoliberalism got organized: A Usable history for resisters, With Special reference to education. The Good Society, 25, 158-171.

Flynn, J. R. (2000). How to Defend Humane Ideals. Nebraska: University of Nebraska Press.

Forrester, J. W. (1971/1995). Counterintuitive Behavior of Social System: An introduction to the concepts of system dynamics, discussing social policies and their derivation from incomplete understanding of complex systems. Original text appeared in the January, 1971, issue of the Technology Review published by the Alumni Association of the Massachusetts Institute of Technology. All figures are taken from World Dynamics by Jay W. Forrester, Pegasus Communications, Waltham MA. http://static.clexchange.org/ftp/documents/ roadmaps/RM1/D-4468-2.pdf

Goodlad, J. (1983). A Place Called School. New York: McGraw Hill.

Graeber, D. (2018). Bullshit Jobs: A Theory. London: Allen Lane/Penguin Books. 
Hamilton, D., Jenkins, D., King, C., MacDonald, B., \& Parlett, M. (Eds.). (1977). Beyond the Numbers Game. London: MacMillan Education.

Harris, J. R. (2006). No Two Alike: Human Nature and Human Individuality. New York: W.W. Norton.

Hattie, J. A. C. (2009). Visible learning: A synthesis of over 800 meta-analyses relating to achievement. London: Routledge, Taylor \& Francis.

Hope, K. (1984). As Others See Us: Schooling and Social Mobility in Scotland and the United States. New York: Cambridge University Press.

Kanter, R. M. (1985). The Change Masters: Corporate Entrepreneurs at Work. Hemel Hempstead: Unwin Paperbacks.

Kapur, N. (2018). NHS disciplinary processes. The Psychologist, October, 31, 4.

Kazdin, A. E. (2006). Arbitrary metrics: Implications for identifying evidencebased treatments. American Psychologist, 61, 42-49.

Klein, N. (2007). The Shock Doctrine: The Rise of Disaster Capitalism. London: Penguin Books.

Klemp, G. O., Munger, M. T., \& Spencer, L. M. (1977). An Analysis of Leadership and Management Competencies of Commissioned and Non-Commissioned Naval Officers in the Pacific and Atlantic Fleets. Boston: McBer.

Lees, S. (1996). Strategic Human Resource Management in Transition Economies. Proceedings of Conference: Human Resource Management: Strategy and Practice. Alma Atat Management School, Alma Atat, Khazaksthan.

Lester, S. (2001). Assessing the self-managing learner: A contradiction in terms? Chapter 26 in J. Raven \& J. Stephenson (Eds.), Competence in the Learning Society. New York: Peter Lang. http://eyeonsociety.co.uk/resources/CILSchapter-26.pdf

Maxwell, J. N. (1969). Sixteen Years On. Edinburgh: Scottish Council for Research in Education.

McKnight, J. (1995). The Careless Society: Community and Its Counterfeits. New York: Basic Books (Perseus Group).

Milgram, S. (1974). Obedience to Authority. London: Tavistock.

Mill, J. S. (1859/1962). Representative Government. London: Dent.

Mõttus, R., \& Rozgonjuk, D. (2019). Development is in the details: Age differences in the big five domains, facets, and nuances. Journal of Personality and Social Psychology. Advance online publication. http://dx.doi.org/10.1037/ pspp0000276.

Mulder, M. (Ed.). (2017). Competence-based Vocational and Professional Education: Bridging the Worlds of Work and Education. Basel, Switzerland: Springer International. http://www.springer.com/us/book/9783319417110 
Nutt, D. (2012) .Drugs Without the Hot Air: Minimising the Harms of Legal and Illegal Drugs. Cambridge, UK. UIT Cambridge.

Ofsted (2017). Bold beginnings: The reception curriculum in a sample of good and outstanding primary schools. Piccadilly Gate, Store Street, Manchester M1 2WD. https://schoolsweek.co.uk/wp-content/uploads/2017/11/28933Ofsted-Early-Years-Curriculum-Report.pdf

O'Reilly, D. (2001). Competence and incompetence in an institutional context. Chapter 22 in J. Raven \& J. Stephenson (Eds.), Competence in the Learning Society. New York: Peter Lang.

O'Reilly, D., Cunningham, L., \& Lester, S. (Eds.). (1999). Developing the Capable Practitioner. London: Kogan Page.

Papierno, P. B. and Ceci, S. J. (2005). Beyond the American context. American Psychologist, 60, $1042-1043$.

Prieler, J. A., \& Raven, J. (2008). Problems in the measurement of change (with particular reference to individual change [gain] scores) and their potential solution using IRT. In J. Raven \& J. Raven (Eds.) Uses and Abuses of Intelligence: Studies Advancing Spearman and Raven's Quest for Non-Arbitrary Metrics. Unionville, New York: Royal Fireworks Press; Edinburgh, Scotland: Competency Motivation Project; Budapest, Hungary: EDGE 2000; Cluj Napoca, Romania: Romanian Psychological Testing Services SRL. (Chapter 7, pp. 173-210). Also available at http://eyeonsociety.co.uk/resources/ UAIChapter7.pdf

Raven, J. (1980a). Parents, Teachers and Children: An Evaluation of an Educational Home Visiting Programme. Edinburgh: Scottish Council for Research in Education.

Raven, J. (1980b). Teetering on the brink of a totalitarian society? New Universities Quarterly, 34, 370-382. http:/ / eyeonsociety.co.uk/resources/teeteringonthebrinkofatotalatariansociety.pdf

Raven, J. (1984). Some limitations of the standards. Evaluation and Program Planning, 7, 363-370.

Raven, J. (1991). The Tragic Illusion: Educational Testing. New York: Trillium Press. www.rfwp.com (now available from the author at 30, Great King Street, Edinburgh EH3 6QH.)

Raven, J. (1993). Managing society: The past belonged to economists: The future belongs to psychologists. In A. Biela, \& L. Pawlowski, Protection of the Environment: Mental Changes and Social Integration Perspectives (pp. 531-563). Lublin, Poland: Central European Center for Behavioral Economics, Technical University of Lublin. Also published in: Journal for Mental Changes, (1995), 1-2, 7-46. 
Raven, J. (1994). Managing Education for Effective Schooling: The Most Important Problem Is to Come to Terms with Values. Unionville, New York: Trillium Press. http:/ / eyeonsociety.co.uk/resources/fulllist.html\#managing_education

Raven, J. (1995). The New Wealth of Nations: A New Enquiry into the Nature and Origins of the Wealth of Nations and the Societal Learning Arrangements Needed for a Sustainable Society. Unionville, New York: Royal Fireworks Press Edinburgh, Scotland: Competency Motivation Project. http:/ / eyeonsociety. co.uk/resources/fulllist.html\#new_wealth

Raven, J. (1997a). Can we discuss policy if nothing is what it seems to be? Journal for Mental Changes, 3(1), 85-103. http:/ / eyeonsociety.co.uk/resources/ hcwdpall.pdf

Raven, J. (1984/1997b). Competence in Modern Society: Its Identification, Development and Release. Unionville, New York: Royal Fireworks Press. (First published in 1984 in London, England, by H. K. Lewis.)

Raven, J. (2001). Facilitating the development of competence (Chapter 18). In J. Raven \& J. Stephenson (Eds.), Competence in the Learning Society. New York: Peter Lang.

Raven, J. (2005). More problems with Gap Closing Philosophy and Research. American Psychologist, 60, 1041-1042. Also available at: http:/ / eyeonsociety. co.uk/resources/MPWCTGP.pdf

Raven, J. (2006a). Comment - Papierno and Ceci Miss the Point: A response to Papierno and Ceci's response to Raven (2005) More Problems with Gap Closing Philosophy and Research. http://eyeonsociety.co.uk/resources/ cpmtp.pdf

Raven, J. (2006b). Undesirable Human Traits? http:/ / eyeonsociety.co.uk/resources/uhts.pdf

Raven, J. (2008). The emergence of hierarchy, domination and centralisation: Reflections on the work of Murray Bookchin. Journal for Perspectives of Economic, Political, and Social Integration, 14(1-2), 11-75. Also available at: http:/ / www.eyeonsociety.co.uk/resources/Bookchin.pdf

Raven. J. (2011). What does it mean to be professional? The Psychologist, 24(8), 560.

Raven, J. (2012a). Competence, education, professional development, psychology, and socio-cybernetics. In G J. Neimeyer (Ed.), Continuing Education: Types, Roles, and Societal Impacts (Chapter 16). Hauppauge, New York: Nova Science Publishers, Inc. http://www.eyeonsociety.co.uk/resources/cpdapa_revised_full_version.pdf

Raven, J. (2012b). Emergence: A paper prepared for the Focolari Conference on Prospects for Research and Treatment in Psychology. Journal for Perspectives of Economic Political and Social Integration: Journal for Mental Changes, 
19(1-2), 91-109. Also available at http:/ /eyeonsociety.co.uk/resources/focolari.pdf and http:/ / eyeonsociety.co.uk/resources/focolari_addendum.pdf Raven, J. (2014). Our incompetent society (with a discussion of some of the competencies needed to transform it). http:/ / eyeonsociety.co.uk/resources/Incompetent-society-v3.pdf Russian translation by Oleg Yarygin: Part I: Baltic Humanitarian Journal (2016) T.5. 4(17) 274-292. http://www.napravo.ru/pages/nauchnye_jurnaly/baltiiskii_gumanitarnyi_jurnal/nauchnye_jurnaly_/ Part II: Azimuth Of Scientific Researches / Pedagogy and Psychology, (2016) ,4(17), 198-205. http://www.napravo.ru/pages/nauchnye_jurnaly/jurnal_vektor_nauki/nomera_jurnala_2013/

Raven, J. (2016). The Pervasive and Pernicious Effects of Neglecting Systems Thinking (especially when combined with a disposition toward fascism). http:/ / eyeonsociety.co.uk/resources/Unwillingness-to-engage-in-systemsthinking.pdf

Raven, J. (2017). Problems with Closing the Gap Philosophy and Research, Baltic Humanitarian Journal, 3, 252-275. Full version at: http:/ / eyeonsociety.co.uk/ resources/Closing-the-Gap-2017-V2.pdf

Raven, J. (2018a). Harnessing social processes for the common good. Journal for Perspectives of Economic, Political, and Social Integration, 24, 9-49. Also available at http:/ / eyeonsociety.co.uk/resources/Harnessing-Social-Processes.pdf

Raven, J. (2018b). How to deal with atrocities invented and perpetrated by public servants? http:/ / eyeonsociety.co.uk/resources/How-to-deal-with-atrocitiesperpetrated-by-Public-Servants-2.pdf

Raven, J. (2018c). Some criminal (if not yet criminalised) misapplications of "science," logic, and power illustrated from the field of early childhood education. http:/ / eyeonsociety.co.uk/resources/Criminal-misapplications-of-science.pdf

Raven, J. (2020). Recent Research Supporting a Specific-motive Based Model of Competence. Contribution to a symposium held in Prague, January 2020. http:/ / eyeonsociety.co.uk/resources/Raven-Mottus-Prague-1-21-20.pdf

Raven, J., \& Stephenson, J. (Eds.). (2001). Competence in the Learning Society. New York: Peter Lang. Many chapters also available at http:/ / eyeonsociety.co.uk/ resources/fulllist.html\#competence_in_the_learning_society

Raven, J., Johnstone, J., \& Varley, T. (1985). Opening the Primary Classroom. Edinburgh: Scottish Council for Research in Education. http:/ / eyeonsociety. co.uk/resources/OTPC-complete.pdf

Revans, R. W. (1977). Action learning and the nature of knowledge. Education and Training, November/December.

Roberts, R. (2018a). Hopeful possibilities of resistance. The Psychologist, 31 (September, 7). https://thepsychologist.bps.org.uk/volume-31/september-2018/ hopeful-possibilities-resistance 
Roberts, R. (2018b) Social influence and malevolent authority: Obedience revisited. In Robinson, K., \& Aronica, L. Creative Schools (Chapter 14). London, UK. Penguin Books.

Rothschild, Lord. (1982). An Enquiry into the Social Science Research Council. London: HMSO.

Sahlberg, P. (2015). Finnish Lessons: What can the world learn from educational change in Finland? New York, USA: Teachers College Press.

Schmidt, F. L., Oh, I.S. \& Shaffer, J.A. (2016). The Validity and Utility of Selection Methods in Personnel Psychology: Practical and Theoretical Implications of 100 Years of Research Findings. Unpublished, available from the authors.

Schön, D. (2001). The crisis of professional knowledge and the pursuit of an epistemology of practice (Chapter 13). In J. Raven \& J. Stephenson (Eds.), Competence in the Learning Society. New York: Peter Lang. Also available at http:/ / eyeonsociety.co.uk/resources/CILS-chapter-13.pdf

Scottish Government. (2014). Children and Young People (Scotland) Act, 2014. Norwich, England: TSO (The Stationery Office). http:/ / www.legislation.gov.uk/ asp/2014/8/pdfs/asp_20140008_en.pdf

Seddon, J. (2008). Systems Thinking in the Public Sector: The Failure of the Reform Regime ... and a Manifesto for a Better Way. Axminster, UK: Triarchy Press.

Shiva, V. (1998). Biopiracy: The Plunder of Nature and Knowledge. London: Green Books.

Spearman, C. (1927). The Abilities of Man: Their Nature and Measurement. London, England: MacMillan.

Spencer, L. M., \& Spencer, S. M. (1993). Competence at Work. New York: Wiley.

Suggate, S. P. (2012). Watering the garden before a rainstorm: The case of early reading instruction. In S. Suggate, \& E. Reese, Contemporary Debates in Childhood Education and Development (Chapter 17). London, England: Routledge.

Webster, D. (2014). Inquiry into benefit sanctions policy beyond the Oakley review. House of Commons Work and Pensions Committee. http://www.cpag. org.uk/sites/default/files/uploads/CPAG-HofC-Wk-Pens-Sanctions-DWevidence-Dec-2014.pdf

Weerts, D. J. (2016). From covenant to contract: Changing conceptions of public research universities in american society. The Good Society, 25, 182-208.

Wilkinson, L., \& Task Force on Statistical Inference. (1999). Statistical methods in psychology journals: Guidelines and explanations. American Psychologist, $54,594-604$.

Winter, D. G., McClelland, D. C., \& Stewart, A. J. (1981). A New Case for the Liberal Arts. San Francisco, CA: Jossey-Bass.

Wolf, A. (1987). Work Based Learning: Trainee Assessment by Supervisors. Bradford, England: MSC Sales, ISCO. 